\title{
Report on Exploration of New FeCrAl Heat Variants with Improved Properties
}

Nuclear Technology

Research and Development

Approved for public release. Distribution is unlimited.

Prepared for

U.S. Department of Energy

Advanced Fuel Campaign

Yukinori Yamamoto

Kenneth Kane

Bruce Pint

Artem Trofimov

Hsin Wang

Oak Ridge National Laboratory

August 2019

M3FT-19OR020202053

ORNL/TM-2019/1290

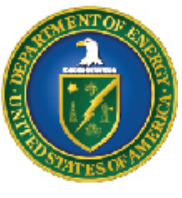




\section{DISCLAIMER}

This information was prepared as an account of work sponsored by an agency of the U.S. Government. Neither the U.S. Government nor any agency thereof, nor any of their employees, makes any warranty, expressed or implied, or assumes any legal liability or responsibility for the accuracy, completeness, or usefulness, of any information, apparatus, product, or process disclosed, or represents that its use would not infringe privately owned rights. References herein to any specific commercial product, process, or service by trade name, trade mark, manufacturer, or otherwise, does not necessarily constitute or imply its endorsement, recommendation, or favoring by the U.S. Government or any agency thereof. The views and opinions of authors expressed herein do not necessarily state or reflect those of the U.S. Government or any agency thereof. 


\section{SUMMARY}

Mechanical and thermophysical properties of wrought FeCrAl base alloys with a concept of accident tolerant fuel (ATF) design for light water reactors (LWR) have been explored. A Gen. II wrought FeCrAl alloy $\mathrm{C} 26 \mathrm{M}$, nominally $\mathrm{Fe}-12 \mathrm{Cr}-6 \mathrm{Al}-2 \mathrm{Mo}-0.2 \mathrm{Si}-0.03 \mathrm{Y}$ in weight percent, is of interest in the current activities, which was downselected as one of the candidate ATF cladding materials. Major target of the current study is to find the effects of various minor alloying additions and their combinations on potential improvement of thin-wall, seamless tube producibility, without losing the expected mechanical and thermal properties in the final products.

Comparisons of lab-scale C26M base alloy heats with minor alloying additions, in terms of microstructure evolution during solidification and thermo-mechanical processing, room-temperature deformability, and high-temperature oxidation resistance in a steam-containing environment, were conducted. It was found that the $\mathrm{Y}$ addition dominantly controlled the formation of the columnar grains in as-cast microstructure, and it caused inhomogeneous material deformation (and therefore microstructure evolution) during the hotprocess. On the other hand, the $\mathrm{Zr}$ addition promoted the formation of equi-axed grains and supported more homogeneous deformation during hot-process as well as a significant stabilization of fine, recrystallized grain structure with $\sim 20-25 \mu \mathrm{m}$ of average grain size. The grain refinement increases the room-temperature ductility, and the grain size stability during exposure at elevated temperature allows a wide process condition in various hot-process, including seamless, thin-wall $\mathrm{FeCrAl}$ tube production (e.g. large drawing reduction per pass, wide tolerance of annealing conditions, etc.). However, the $\mathrm{Zr}$ addition was also found to decrease the oxidation resistance during ramp test in steam environment up to $1450^{\circ} \mathrm{C}$, whereas the $\mathrm{Y}$ added alloys (with no $\mathrm{Zr}$ ) showed improved oxidation resistance with protective alumina-scale formation at the same test condition. Because of the observed improved properties, the present results still hold an opportunity to optimize the balanced and further improved properties of $\mathrm{C} 26 \mathrm{M}$ base alloy by fine-tuning minor alloying additions. In addition, the $0.02 \mathrm{wt} \% \mathrm{C}$ and $0.2 \mathrm{wt} \% \mathrm{Mn}$ additions, simulating an industrialgrade alloy production, were found to show very little impact on changing the properties, indicating that additional compositional tolerances can be applied in the alloy specification.

As part of the updating efforts of the FeCrAl handbook, thermophysical property measurements of C26M alloy were conducted. The thermal expansion coefficient, specific heat capacity, and thermal diffusivity of the $\mathrm{C} 26 \mathrm{M}$ alloy were measured as a function of temperature, and the results showed a good agreement with the other FeCrAl alloys with similar composition range reported previously. The data will be used for the next update of the handbook. 


\section{FIGURES}

Figure 1. Processing route and target size of each step (starting from $13 \mathrm{~mm}$ diameter ingot).................. 3

Figure 2. Temperature profile of the ramp test. ..................................................................................... 4

Figure 3. Specimen machining plan from C26M2 rod..................................................................... 5

Figure 4. As-cast macrostructures of C26M base alloys with $13 \mathrm{~mm}$ diameter. ...................................... 7

Figure 5. As-cast macrostructures of C26M base alloys with $25 \mathrm{~mm}$ diameter. ..................................... 8

Figure 6. Cross-sectional macrostructure after hot-forging at $800^{\circ} \mathrm{C}$ with $40 \%$ reduction......................... 9

Figure 7. Cross-sectional macrostructure after hot-forging at $800^{\circ} \mathrm{C}$ with $70 \%$ reduction....................... 10

Figure 8. Cross-sectional microstructures of the rolled-and-annealed alloys at three different final

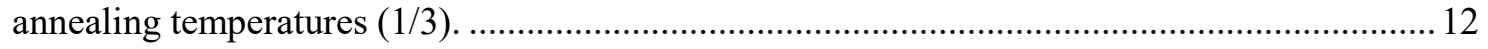

Figure 9. Average grain size of the rolled-and-annealed materials....................................................... 15

Figure 10. Room temperature tensile properties of all alloys in the present study................................. 16

Figure 11. Room temperature tensile properties plotted as a function of average grain size. ................... 17

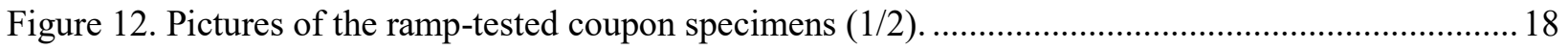

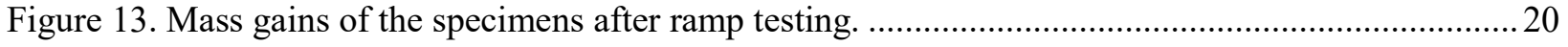

Figure 14. Low and high magnification optical micrographs of the cross-sectional surface region of the ramp-tested coupon specimens $(1 / 2)$.

Figure 15. Thermo-physical properties of C26M2 as a function of temperature; (a) coefficient of thermal expansion, (b) specific heat capacity, and (c, d) thermal diffusivity. 


\section{TABLES}

Table 1. Nominal composition of C26M base alloys in the present study ...............................................

Table 2. Combinations of the key additional elements and minor elements.............................................. 2

Table 3. Target range and analyzed compositions of C26M2. ............................................................. 5

Table 4. Average grain size of the rolled-and-annealed materials; the highlighted samples were used for the tensile property evaluation and the ramp testing, and the masked samples showed not fully recrystallized microstructure 


\section{ACRONYMS}

$\begin{array}{ll}\text { AFC } & \text { Advanced Fuels Campaign } \\ \text { ASTM } & \text { American Society for Testing and Materials } \\ \text { ATF } & \text { Accident Tolerant Fuel } \\ \text { BCC } & \text { Body Centered Cubic } \\ \text { CTE } & \text { Coefficient of Thermal Expansion } \\ \text { DOE } & \text { US Department of Energy } \\ \text { DSC } & \text { Differential Scanning Calorimetry } \\ \text { LOCA } & \text { Loss Of Coolant Accident } \\ \text { LWR } & \text { Light Water Reactor } \\ \text { NE } & \text { Nuclear Energy } \\ \text { ORNL } & \text { Oak Ridge National Laboratory } \\ \text { TE } & \text { Total plastic Elongation } \\ \text { SATS } & \text { Sever Accident Test Station } \\ \text { SiC } & \text { Silicon Carbide } \\ \text { UE } & \text { Uniform plastic Elongation } \\ \text { UTS } & \text { Ultimate Tensile Strength } \\ \text { YS } & \text { Yield Strength }\end{array}$




\section{ACKNOWLEDGMENTS}

The authors are grateful to Andy Nelson, Kory Linton, Kurt Terrani, and Kevin Field of Oak Ridge National Laboratory (ORNL) for their helpful discussions and management, to Mike Howell, Brandon Johnston, Ian Stinson, Cecil Carmichael, Greg Cox, Kevin Hanson, Daniel Moore, Dustin Heidel of ORNL for their technical support on experimental efforts at ORNL, and to Russ Fawcett, Rau Rebak, and Chuck Paone of GE/GNF, for their supports on development of ATF wrought FeCrAl alloys. The time spent by Xunxiang $\mathrm{Hu}$ and Frank Chen of ORNL in reviewing this report is also greatly appreciated.

This work was supported by the US Department of Energy Office of Nuclear Energy (DOE-NE) Advanced Fuels Campaign (AFC). 


\section{REPORT ON EXPLORATION OF NEW FECRAL HEAT VARIANTS WITH IMPROVED PROPERTIES}

\section{Introduction}

The development of alloys for nuclear-grade enhanced accident-tolerant fuel (ATF) cladding targets a new, metal-based structural material for nuclear fuel cladding in light water reactors (LWRs). FeCrAl alloys were selected as candidate ATF cladding alloys based on their excellent oxidation resistance in hightemperature steam environments at up to $1475^{\circ} \mathrm{C}$ (resulting from sufficient amounts of $\mathrm{Cr}$ and $\mathrm{Al}$ additions) compared with industry-standard zirconium alloys, which do not have comparable high-temperature tolerances $[1,2,3,4]$. Development efforts for ATF FeCrAl alloys have been pursued since FY 2013 under the Fuel Cycle Research and Development program [5]. After comprehensive evaluations of model Fe-CrAl-Y alloys (Gen. I) and engineering $\mathrm{FeCrAl}$ alloy series (Gen. II) with a wide range of major and minor alloy compositions, an alloy consisting of Fe-12Cr-6Al-2Mo-0.2Si-0.03Y, wt.\% (identified as "C26M") was down-selected for seamless, thin-wall tube production to be used as an ATF cladding.

Research has been focused on achieving a balance between high-temperature performance and tube fabricability [6]. Body centered cubic (BCC) Fe-based materials with $\mathrm{Cr}$ and Al additions typically suffer from poor ductility because of their relatively high ductile-brittle transition temperatures [7]. Microstructural stability of the refined grain or subgrain structure at high temperatures is critical to maintaining both the fabricability of the alloys during tube production and the mechanical properties of the final tube products. Previous efforts successfully produced seamless, thin-wall FeCrAl alloy tubes combined with the expected fine grain structure in the final products through commercially available fabrication process (including a vacuum induction melting, hot-isostatic pressing, extrusion, gun-drilling, drawing and annealing [6]). However, because of relatively narrow process window to achieve the balance of the processability and the properties in the C26M tube products, further demands appeared to increase the cost-effectiveness, by applying a large reduction in each drawing pass, wide tolerance of intermediate annealing conditions, increased material yield through less susceptibility of unexpected crack formation during drawing process, together with controlling the fine grain structure as well as sufficiently high surface protection at elevated temperature.

Based on such demands, the current study focuses on improving various properties related to the production and the service of $\mathrm{C} 26 \mathrm{M}$ base alloy through minor alloying additions. Targets are to achieve fine grain structure and high microstructure stability for better processability of thin-wall tube products, combining with sufficiently high oxidation resistance to make the material survive in accident scenarios (such as lossof-coolant-accident, LOCA). Controlling such properties only through minor alloying additions should minimize the required changes in the current production portfolio or a requirement of potential modification of the existing processing equipment. The minor alloying elements of interest in the current study include $\mathrm{Y}, \mathrm{Ce}, \mathrm{Zr}, \mathrm{C}$, and $\mathrm{Mn}$, because of multiple reasons listed below;

- The Y addition effectively improves the stability of protective alumina-scale [8],

- $\quad$ The Ce addition promotes equi-axed grain structure in as-cast ferritic stainless steels [9],

- $\quad$ The Zr addition stabilizes the grain structure in ferritic stainless steels [10], and

- The additions of $C$ and $M n$ are to simulate an industrial-grade steel product.

Microstructure evolution, tensile properties at room temperature, and oxidation resistance will be evaluated and then correlated with the minor alloying additions and their combinations. 
In addition, measurements of $\mathrm{C} 26 \mathrm{M}$ thermophysical properties were conducted in this study as a part of the updating effort of FeCrAl handbook prepared previously [8]. The obtained results related to thermal expansion, specific heat capacity, and thermal diffusivity as a function of temperature will be presented.

\section{Experimental Procedure}

\subsection{Alloy preparation}

Total 12 lab-scale heats based on C26M (Fe-12Cr-6Al-2Mo-0.2Si-0.03Y, wt.\%) with various combinations of minor alloying additions have been prepared by arc-melting with pure element feedstocks combined with a pre-melted Fe-Y alloy. Nominal compositions of the lab-scale heats were summarized in Table 1. The combinations of the key additional elements ( $\mathrm{Y}, \mathrm{Ce}$ and $\mathrm{Zr}$ ) and minor elements $(\mathrm{C}$ and $\mathrm{Mn})$ and the corresponding sample identification are also shown in Table 2.

Table 1. Nominal composition of C26M base alloys in the present study.

\begin{tabular}{ccccccccccccc}
\hline \multirow{2}{*}{ Name } & \multirow{2}{*}{ Short ID } & \multicolumn{8}{c}{ Nominal composition, wt.\% } & \multirow{2}{*}{ Remarks } \\
\cline { 2 - 13 } & & $\mathrm{Fe}$ & $\mathrm{Cr}$ & $\mathrm{Al}$ & $\mathrm{Mo}$ & $\mathrm{Si}$ & $\mathbf{Y}$ & $\mathbf{C e}$ & $\mathbf{Z r}$ & $\mathbf{C}$ & Mn & \\
\hline C26M-A & $\mathbf{0}$ & 79.8 & 12 & 6 & 2 & 0.2 & & & & & 13 mm dia. \\
\hline C26M-B & Ce & 79.77 & 12 & 6 & 2 & 0.2 & & $\mathbf{0 . 0 3}$ & & & 13 mm dia. \\
\hline C26M3 & Y & 79.7 & 12 & 6 & 2 & 0.2 & $\mathbf{0 . 1}$ & & & & 25 mm dia. \\
\hline C26M-E & Y-2 & 79.7 & 12 & 6 & 2 & 0.2 & $\mathbf{0 . 1}$ & & & & & 13 mm dia. \\
\hline C26M-C & YCe & 79.67 & 12 & 6 & 2 & 0.2 & $\mathbf{0 . 1}$ & $\mathbf{0 . 0 3}$ & & & 13 mm dia. \\
\hline C26M-G & Y-CM & 79.48 & 12 & 6 & 2 & 0.2 & $\mathbf{0 . 1}$ & & & $\mathbf{0 . 0 2}$ & $\mathbf{0 . 2}$ & 13 mm dia. \\
\hline C26Mx & YCe-CM & 79.45 & 12 & 6 & 2 & 0.2 & $\mathbf{0 . 1}$ & $\mathbf{0 . 0 3}$ & & $\mathbf{0 . 0 2}$ & $\mathbf{0 . 2}$ & 25 mm dia. \\
\hline C26M-F & Z & 79.5 & 12 & 6 & 2 & 0.2 & & & $\mathbf{0 . 3}$ & & & 13 mm dia. \\
\hline C26M-D & ZCe & 79.47 & 12 & 6 & 2 & 0.2 & & $\mathbf{0 . 0 3}$ & $\mathbf{0 . 3}$ & & & 13 mm dia. \\
\hline C26M-H & ZCe-CM & 79.25 & 12 & 6 & 2 & 0.2 & & $\mathbf{0 . 0 3}$ & $\mathbf{0 . 3}$ & $\mathbf{0 . 0 2}$ & $\mathbf{0 . 2}$ & 13 mm dia. \\
\hline C26MZ & YZCe & 79.37 & 12 & 6 & 2 & 0.2 & $\mathbf{0 . 1}$ & $\mathbf{0 . 0 3}$ & $\mathbf{0 . 3}$ & & & 25 mm dia. \\
\hline C26MZx & YZCe-CM & 79.15 & 12 & 6 & 2 & 0.2 & $\mathbf{0 . 1}$ & $\mathbf{0 . 0 3}$ & $\mathbf{0 . 3}$ & $\mathbf{0 . 0 2}$ & $\mathbf{0 . 2}$ & 25 mm dia. \\
\hline
\end{tabular}

Table 2. Combinations of the key additional elements and minor elements.

\begin{tabular}{|c|c|c|c|}
\hline \multirow{2}{*}{ Type } & \multirow{2}{*}{ Key third elements } & \multicolumn{2}{|c|}{ Minor elements } \\
\hline & & Without $\mathrm{C}+\mathrm{Mn}$ & With $0.02 \mathrm{C}+0.2 \mathrm{Mn}$ \\
\hline \multirow{4}{*}{ Without $\mathrm{Zr}$} & 0 & C26M-A (0) & - \\
\hline & $0.03 \mathrm{Ce}$ & C26M-B (Ce) & - \\
\hline & $0.1 \mathrm{Y}$ & C26M3/C26M-E (Y/Y-2) & C26M-G (Y-CM) \\
\hline & $0.1 \mathrm{Y}+0.03 \mathrm{Ce}$ & C26M-C (YCe) & C26Mx (YCe-CM) \\
\hline \multirow{3}{*}{ With Zr } & $0.3 \mathrm{Zr}$ & C26M-F (Z) & - \\
\hline & $0.3 \mathrm{Zr}+0.03 \mathrm{Ce}$ & C26M-D (ZCe) & C26M-H (ZCe-CM) \\
\hline & $0.1 \mathrm{Y}+0.3 \mathrm{Zr}+0.03 \mathrm{Ce}$ & C26MZ (YZCe) & C26MZx (YZCe-CM) \\
\hline
\end{tabular}

The alloys were arc-melted in a back-filled inert gas atmosphere (with Ar gas) to produce button-shape ingots which were flipped and melted repeatedly for 5 times to ensure a well-homogenized condition in the ingots. This melting process caused a loss of Y, so that an excess amount of $\mathrm{Y}(0.1 \mathrm{wt} . \%)$ was added to expect the final $\mathrm{Y}$ content to be $\sim 0.03 \mathrm{wt} . \%$. The button ingots were then arc-melted again and drop-cast into a water-cooled, cylindrical-shape $\mathrm{Cu}$-mold with a size of $13 \mathrm{~mm}$ in diameter $\mathrm{x} 76 \mathrm{~mm}$ in length or 25 
$\mathrm{mm}$ in diameter $\mathrm{x} 120 \mathrm{~mm}$ in length. After cutting of the hot-top of the ingots, they were homogenized at $1200^{\circ} \mathrm{C}$ for $1 \mathrm{~h}$ in air, followed by air cooling. The ingots with $13 \mathrm{~mm}$ diameter were sectioned into a halflength, soaked at $800^{\circ} \mathrm{C}$ for more than $30 \mathrm{~min}$ in air, and then applied hot-forging from the side of the cylindrical sample, targeting plate-shape samples with $\sim 8 \mathrm{~mm}$ in thickness (40\% reduction). After sectioning a small piece for cross-sectional microstructure observation, additional hot-forging at $800^{\circ} \mathrm{C}$ (after soaking for $30 \mathrm{~min}$ in air) was applied to prepare the plates with $\sim 4 \mathrm{~mm}$ in thickness (total $70 \%$ reduction). After sectioning another small piece for microstructure observation, a hot-rolling at $800^{\circ} \mathrm{C}$ (after soaking for $30 \mathrm{~min}$ in air) targeting the final thickness of $\sim 1.3 \mathrm{~mm}$ (total $90 \%$ thickness reduction). The processing route was summarized in Fig. 1. A similar thermo-mechanical process was applied to the ingots with $25 \mathrm{~mm}$ diameter, although the final thickness of the ingots was $1.5 \mathrm{~mm}$ (total $94 \%$ thickness reduction).

The plate samples were subsequently annealed at $800^{\circ} \mathrm{C}$ for $30 \mathrm{~min}$ in air, followed by air-cool. A part of each plate was sectioned and then additionally annealed at $800^{\circ} \mathrm{C}$ for $30 \mathrm{~min}$ (total $60 \mathrm{~min}$ ) or $900^{\circ} \mathrm{C}$ for $30 \mathrm{~min}$, to evaluate the effect of annealing temperature and time on recrystallization and grain coarsening. Further annealing at $1000^{\circ} \mathrm{C}$ for $30 \mathrm{~min}$ was also applied for the selected alloys.

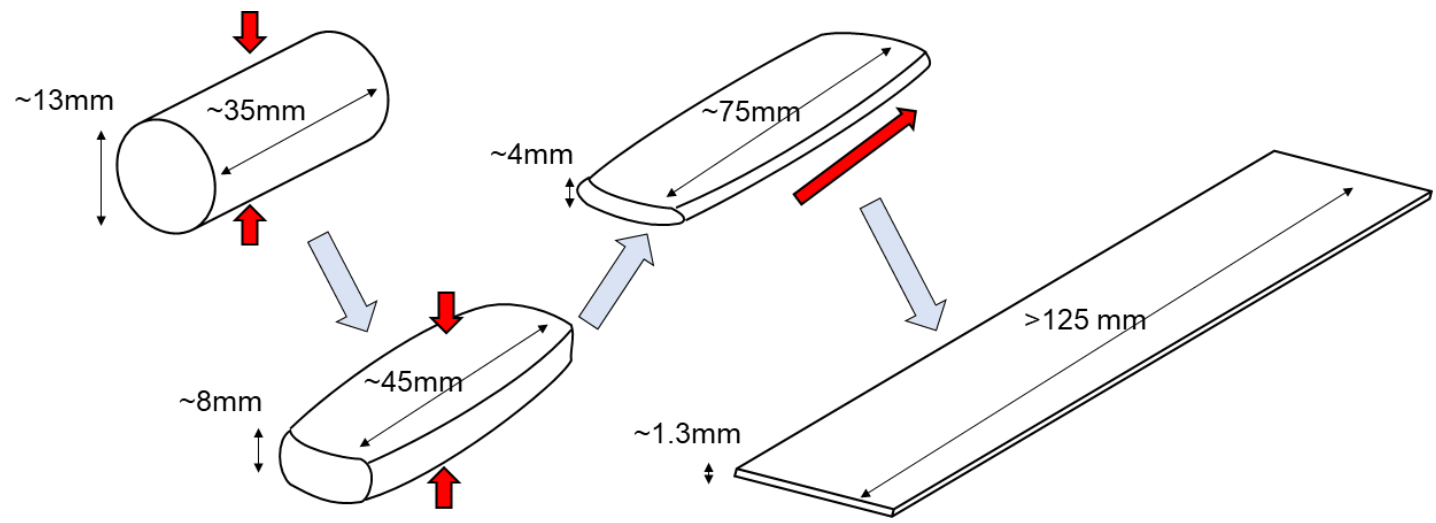

Figure 1. Processing route and target size of each step (starting from $13 \mathrm{~mm}$ diameter ingot).

\subsection{Microstructure characterization}

Macroscopic characterization of the grain structure after solidification (= as-cast), $40 \%$ hot-forging (HF), and $70 \% \mathrm{HF}$ were conducted with the cross-sectional samples which were mounted into an epoxy resin (other than $25 \mathrm{~mm}$ diameter as-cast ingot), ground by using $\mathrm{SiC}$ papers up to \#800, and then polished with $0.3 \mu \mathrm{m}$ alumina powder. The polished samples were immersed into an etching solution consisting of $\mathrm{H}_{2} \mathrm{O}$ $(20 \mathrm{ml}), \mathrm{HCl}(30 \mathrm{ml}), \mathrm{HNO}_{3}(10 \mathrm{ml})$ and $\mathrm{HF}(2$ drops, less than $1 \mathrm{ml})$, for more than $10 \mathrm{sec}$, followed by rinsing with a flowing water. The images were taken by a light optical microscope or a desktop flatbed scanner (CanoScan LiDE 100, Canon) connected with a PC.

Microstructure characterization of the rolled-and-annealed samples were conducted by using crosssectional specimens. The plates were sectioned perpendicular to the rolling direction, and the sectioned pieces were mounted into an epoxy resin. The mounted specimens were ground and polished in the same manner of the metallographic sample preparation described above, and then etched with a solution of $\mathrm{H}_{2} \mathrm{O}$ $(50 \mathrm{ml}), \mathrm{HNO}_{3}(10 \mathrm{ml})$ and $\mathrm{HF}(2$ drops, less than $1 \mathrm{ml})$, for more than $30 \mathrm{sec}$, followed by rinsing with a flowing water. Microstructure was observed by a light optical microscope. The averaged grain size was obtained from a mean-intercept method (following ASTM E112) with more than 300 grains measured for each specimen. 


\subsection{Tensile test}

Room temperature (RT) tensile test was conducted by using selected rolled-and-annealed specimens. A miniature dog-bone shape specimen (SS-3, $0.76 \mathrm{~mm}$ thickness $\times 1.5 \mathrm{~mm}$ width $\times 7.6 \mathrm{~mm}$ length at the gage portion) was prepared by an electro-discharged machining and a hand-grinding with a surface finish up to \#600. The test was conducted by using a tensile test frame equipped with a screw-driven cross-head, and the strain rate of 10-3 s-1 was controlled by the constant cross-head speed. No extensometer was used in this study.

\subsection{Ramp test}

A ramp test with a flowing steam environment was conducted by using selected rolled-and-annealed specimens. A coupon specimen (1 mm thickness x $10 \mathrm{~mm}$ width x $20 \mathrm{~mm}$ length) was prepared from each plate sample by electro-discharge machining and hand grinding with a surface finish up to \#600. A hole with $1.6 \mathrm{~mm}$ diameter was made for each coupon which was used to support the coupon, by a SiC rod, inside an alumina tube. The weights of alloy coupons were measured at this point in order to evaluate the mass gain/loss after testing. No more than three coupons were set in the alumina tube for each ramp test cycle to avoid any unexpected interaction among the coupons within the limited diameter of the tube. After supplying the flowing steam inside the alumina tube, it was heated from RT to $600^{\circ} \mathrm{C}$ with $20^{\circ} \mathrm{C} / \mathrm{min}$ heating rate, held at $600^{\circ} \mathrm{C}$ for $1 \mathrm{~min}$, heated from 600 to 1400 or $1450^{\circ} \mathrm{C}$ with $15^{\circ} \mathrm{C} / \mathrm{min}$, held at the temperature for $1 \mathrm{~min}$, and then cooled to RT (as shown in Fig. 2). The heat cycle simulated a potential LOCA event inside LWRs.

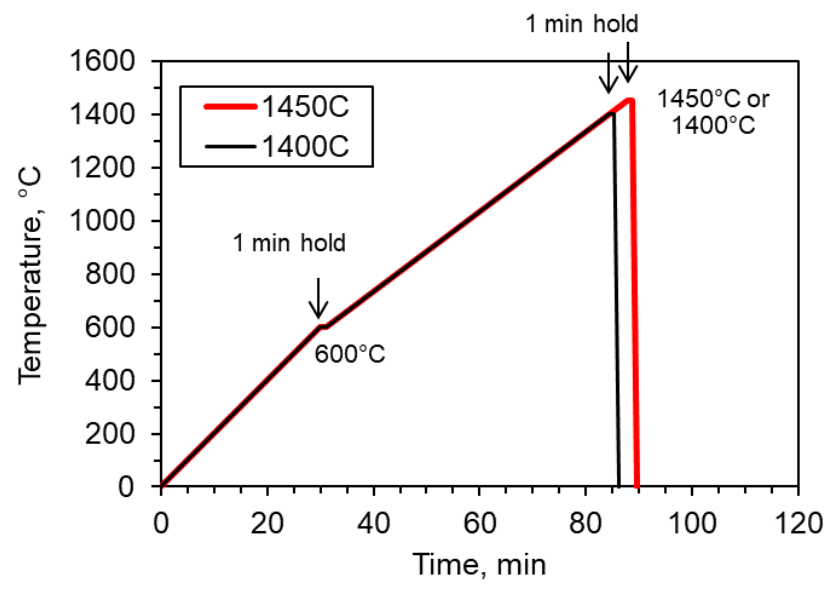

Figure 2. Temperature profile of the ramp test.

After measuring the weights and taking pictures of the tested coupons, cross-sectional microstructure characterization was conducted. The coupons were sectioned and mounted into an epoxy resin, ground by using $\mathrm{SiC}$ papers up to \#800, and then polished with $0.3 \mu \mathrm{m}$ alumina powder and $0.05 \mu \mathrm{m}$ colloidal silica. The cross-sectional surface oxide was observed without etching, by using a light optical microscope.

\subsection{Thermophysical property measurements}

Thermophysical properties such as thermal expansion, heat capacity, and thermal diffusivity of C26M2 (heat \#17025001, the analyzed chemistry is listed in Table 3) were obtain using dilatometry, differential scanning calorimetry (DSC), and laser flash method, respectively. The specimens for three different tests 
were machined from a $\mathrm{C} 26 \mathrm{M} 2$ rod specimen with $13 \mathrm{~mm}$ in diameter which was prepared through a vacuum induction melting and a hot-isostatic pressing, followed by a hot-pressing and a rotary forging for rod shape production, and then final-annealing at $800^{\circ} \mathrm{C}$. The specimen machining plan is shown in Fig. 3 .

Table 3. Target range and analyzed compositions of C26M2.

\begin{tabular}{cccccccccc}
\hline \multirow{2}{*}{ ID } & \multirow{2}{*}{ Heat \# } & \multirow{7}{*}{ Condition } & $\mathrm{Cr}$ & $\mathrm{Al}$ & $\mathrm{Y}$ & $\mathrm{Mo}$ & $\mathrm{Si}$ & $\mathrm{C}$ & $\mathrm{S}$ \\
\cline { 3 - 10 } & & Analyzed & $\mathbf{1 1 . 8 7}$ & $\mathbf{6 . 2 2}$ & $\mathbf{0 . 0 3}$ & $\mathbf{1 . 9 8}$ & $\mathbf{0 . 2 0}$ & $<\mathbf{0 . 0 1}$ & $<\mathbf{0 . 0 0 5}$ \\
\cline { 3 - 9 } C26M2 & \multirow{3}{*}{17025001} & Target & 12 & 6 & 0.03 & 2 & 0.02 & - & - \\
\cline { 3 - 9 } & & Max. & 12.25 & 6.25 & 0.07 & 2.25 & 0.25 & 0.01 & 0.005 \\
& & Min. & 11.75 & 5.75 & 0.03 & 1.75 & 0.15 & - & - \\
\hline
\end{tabular}

* Measured by induction coupled plasma optical emission spectroscopy (most of the elements) and combustion analysis (C and S).

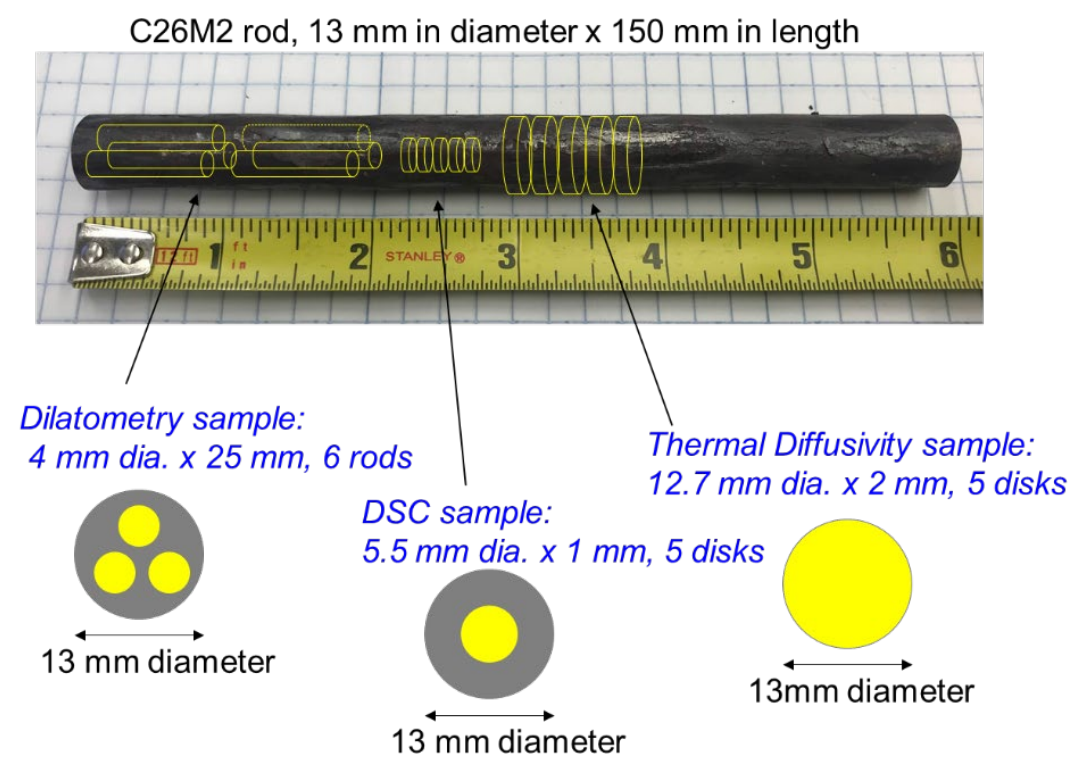

Figure 3. Specimen machining plan from C26M2 rod.

Dilatometry samples were cylindrical rods, ca. $25 \mathrm{~mm}$ long. The thermal expansion was measured in the temperature range from 50 to $1200^{\circ} \mathrm{C}$ at $3^{\circ} \mathrm{C} / \mathrm{min}$ with a Theta Dilatronic IX differential dilatometer, which is horizontal dual pushrod dilatometer. A sapphire standard was used as the reference. Before each run the vacuum-tight dilatometer is pumped down and back filled with helium two times, and then pumped down a third time to below 200 mTorr. During the run, titanium-gettered helium is flowed through the system at $15 \mathrm{sccm}$.

The specific heat capacity was measured in the temperature range from 50 to $1050^{\circ} \mathrm{C}$ at $10^{\circ} \mathrm{C} / \mathrm{min}$ with a Netzsch DSC 404C. Platinum pans and lids were used during the DSC runs, and an empty Pt pan with lid served as a reference. Prior to the experiments, the DSC cell was purged with argon. The heating and cooling were conducted with flowing titanium-gettered argon, and the oxygen partial pressure was kept below $10^{-8} \mathrm{appm}$. Upon completion of a heating cycle, samples were held at the maximum temperature for 30 min before starting a cooling cycle.

Diffusivity measurements were performed in the temperature range from 25 to $1050^{\circ} \mathrm{C}$ using a Netzsch LFA 457 laser flash system. Samples were ca. $2 \mathrm{~mm}$ thick and $12.7 \mathrm{~mm}$ in diameter and were coated with 
a thin layer of graphite using graphite spray to enhance the signal. The testing was performed under flowing argon purge. Three measurements were performed at each temperature set point. The diffusivity values are calculated based on the sample thickness and temperature rise curve after each laser pulse.

\section{Results and Discussion}

\subsection{Microstructure evolution}

\subsubsection{As-cast macrostructure}

Cross-sectional macrostructure of as-cast ingots are shown in Figs. 4 and 5, for $13 \mathrm{~mm}$ and $25 \mathrm{~mm}$ diameter ingots, respectively. C26M-E (Y-2, $13 \mathrm{~mm}$ diameter) and C26M3 (Y, $25 \mathrm{~mm}$ diameter) are nominally the same as "C26M" alloy reported previously (e.g. ref. 6), which showed a columnar grain structure elongated along radial axis and reached entire length from the ingot surface to the center of the ingot. There was no significant difference in the macrostructure between the ingots with $13 \mathrm{~mm}$ and $25 \mathrm{~mm}$ diameter.

C26M-A (0), containing no reactive elements, showed very coarse, columnar grain structure compared to the original C26M with 0.03 wt.\% Y (C26M3 and C26M-E). C26M-B (Ce) containing 0.03 wt.\% Ce showed very limited effect on refining the columnar grains, whereas the combined additions of $\mathrm{Y}$ and $\mathrm{Ce}$ in C26M-C (YCe) resulted in further refined columnar grains compared to C26M3 (Y) and C26M-E (Y-2). The Zr solo-addition in C26M-F (Z), on the other hand, showed the formation of equi-axed grain formation near the center of the ingot, and the combined additions of $\mathrm{Zr}$ and Ce in C26M-D (ZCe) resulted in extending the equi-axed grain region than the $\mathrm{Zr}$ solo-addition. When combined $\mathrm{Y}, \mathrm{Zr}$, and $\mathrm{Ce}$ in $\mathrm{C} 26 \mathrm{MZ}$ (YZCe), the macrostructure was fully covered by columnar grains again, with relatively finer grain structure than the original C26M3 (Y).

The additions of $0.02 \mathrm{wt} \% \mathrm{C}$ and $0.2 \mathrm{wt} \% \mathrm{Mn}$ did not significantly impact on as-cast microstructure evolution. C26M-G (Y-CM), C26Mx (YCe-CM), and C26MZx (YZCe-CM) showed a columnar microstructure similar to the alloys without $\mathrm{C}$ and Mn additions in C26M-E (Y-2), C26M-C (YCe), and C26MZ (YZCe), respectively. It should be noted that C26M-G (Y-CM) showed a little coarser columnar grain structure than C26M-E (Y), and C26M-H (ZCe-CM) also showed relatively coarse equi-axed grains compared to C26M-F (Z), indicating that the combined additions of $\mathrm{C}$ and $\mathrm{Mn}$ may have an effect on slightly suppressing the grain refinement.

Based on the results, it is obvious that the $\mathrm{Y}$ addition promoted the formation of columnar grains. The Ce addition is known to promote the formation of equi-axed grains in the solidification microstructure of ferritic stainless steels in the range of 0.02 to 0.04 wt.\% addition [9]. However, the Ce solo-addition to Fe$12 \mathrm{Cr}-6 \mathrm{Al}-2 \mathrm{Mo}-0.2 \mathrm{Si}$ alloy did not show a strong impact on changing in the as-cast grain structure. Instead, the $\mathrm{Zr}$ addition exhibited a positive effect on promoting equi-axed grain formation during solidification. Note that the $\mathrm{Zr}$ addition is expected to refine the grain structure as well as a stabilization of fine grain structure at elevated temperatures after applying thermo-mechanical treatments [10]. The addition of Ce into the $\mathrm{Y}, \mathrm{Zr}$, or $\mathrm{Y}+\mathrm{Zr}$ containing alloys refined the microstructure, which indicated that Ce increased the nucleation frequency by forming complex oxides with Si and Al [9], although it does not have much effect on the defeating the strong impact from the $\mathrm{Y}$ or $\mathrm{Zr}$ additions which strongly promoted the formation of the columnar or equi-axed grain structure, respectively. The additions of $\mathrm{C}$ and $\mathrm{Mn}$ did not show a strong impact on changing in the type of as-cast grain structure, which would allow additional compositional tolerances in the $\mathrm{C} 26 \mathrm{M}$ alloy specification. 


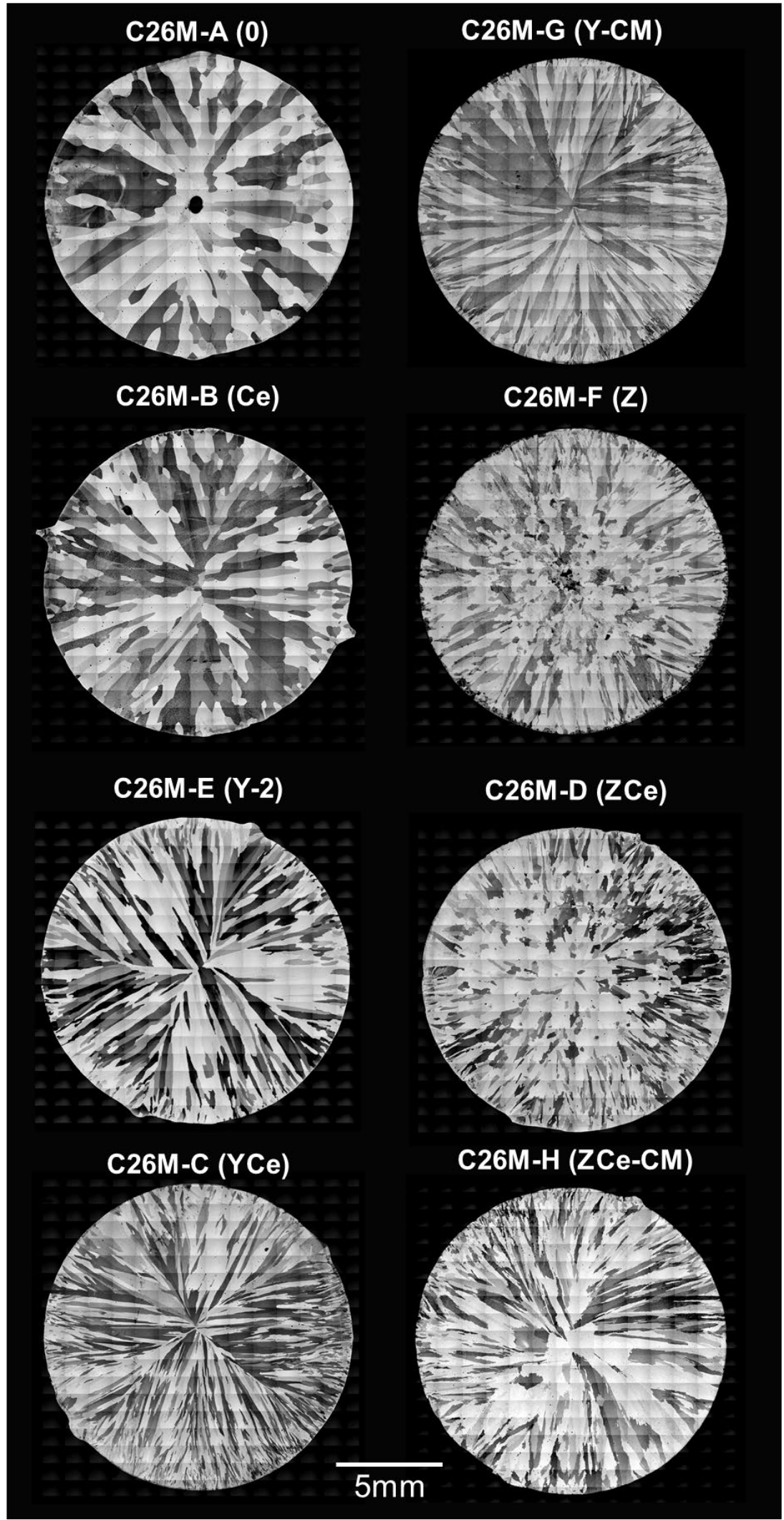

Figure 4. As-cast macrostructures of C26M base alloys with $13 \mathrm{~mm}$ diameter. 


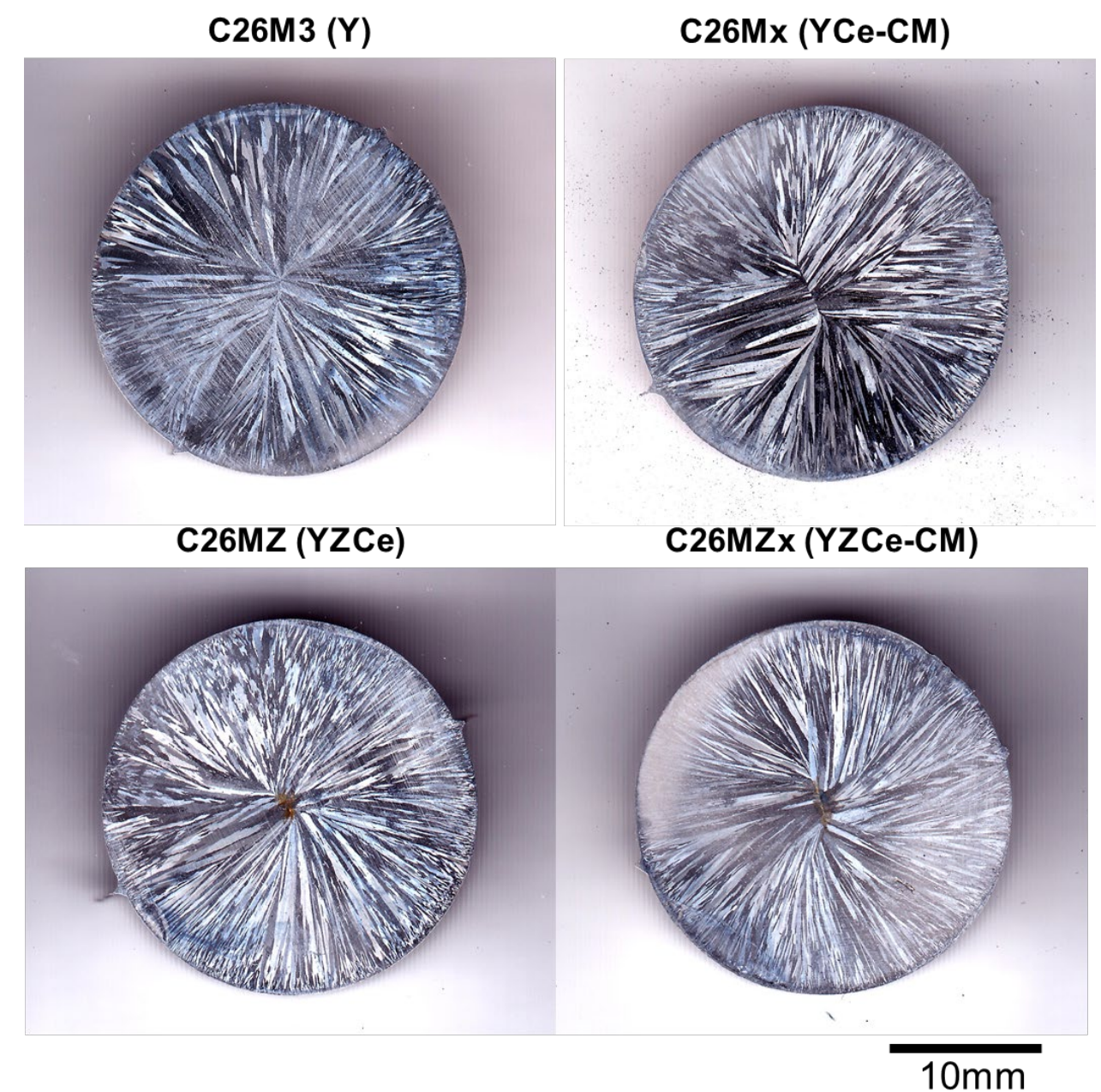

Figure 5. As-cast macrostructures of C26M base alloys with $25 \mathrm{~mm}$ diameter.

\subsubsection{Deformation macrostructure}

Cross-sectional macroscopic images of hot-forged ingots at $800{ }^{\circ} \mathrm{C}$ with $40 \%$ and $70 \%$ reduction are shown in Figs. 6 and 7, respectively. All images of 40\% deformed materials showed inhomogeneous deformation characteristics which could be categorized into two different groups; one showed fine, dynamically recrystallized grain bands along with the diagonal axes indicating that a macroscopic shear deformation was dominant [in C26M-A (0), -B (Ce), -E (Y-2), -C (YCe), and -G (Y-CM)], and the others exhibited no obvious fine grain band formation across the cross-sectional views but rather a large distortion in the entire area of the material along with the compressive manner [in C26M-F (Z), -D (ZCe), and -H (ZCe-CM)]. The former alloy group exhibited a columnar grain structure in the as-cast state, whereas the latter alloy group contained a large region of equi-axed grains. These results suggest that the columnar grains promoted strain concentration/segregation in the early stage of hot-deformation process, and the refinement of columnar grains (e.g. the additions of $\mathrm{Y}$ or $\mathrm{Y}+\mathrm{Ce}$ ) would not help dispersing such macroscopic strain segregation. There was no premature failure attributed to such strain concentration in the present forging process, possibly due to dynamic recrystallization accelerated further strain concentration into the soft, fine grain regions. However, such deformation characteristics would narrow the process window of the hot-process and lead to inhomogeneous microstructure evolution. On the other hand, the other alloys containing $\mathrm{Zr}$ and 
showing equi-axed grains in as-cast microstructure could avoid such strain segregation and disperse the deformation into much wider area than the former alloy group. Since the alloys did not show dynamically recrystallized grains, possibly due to stabilization of the deformed grains through the $\mathrm{Zr}$ addition, the deformed area could be work-hardened and promoted the dispersion of macroscopic deformation in in the materials.

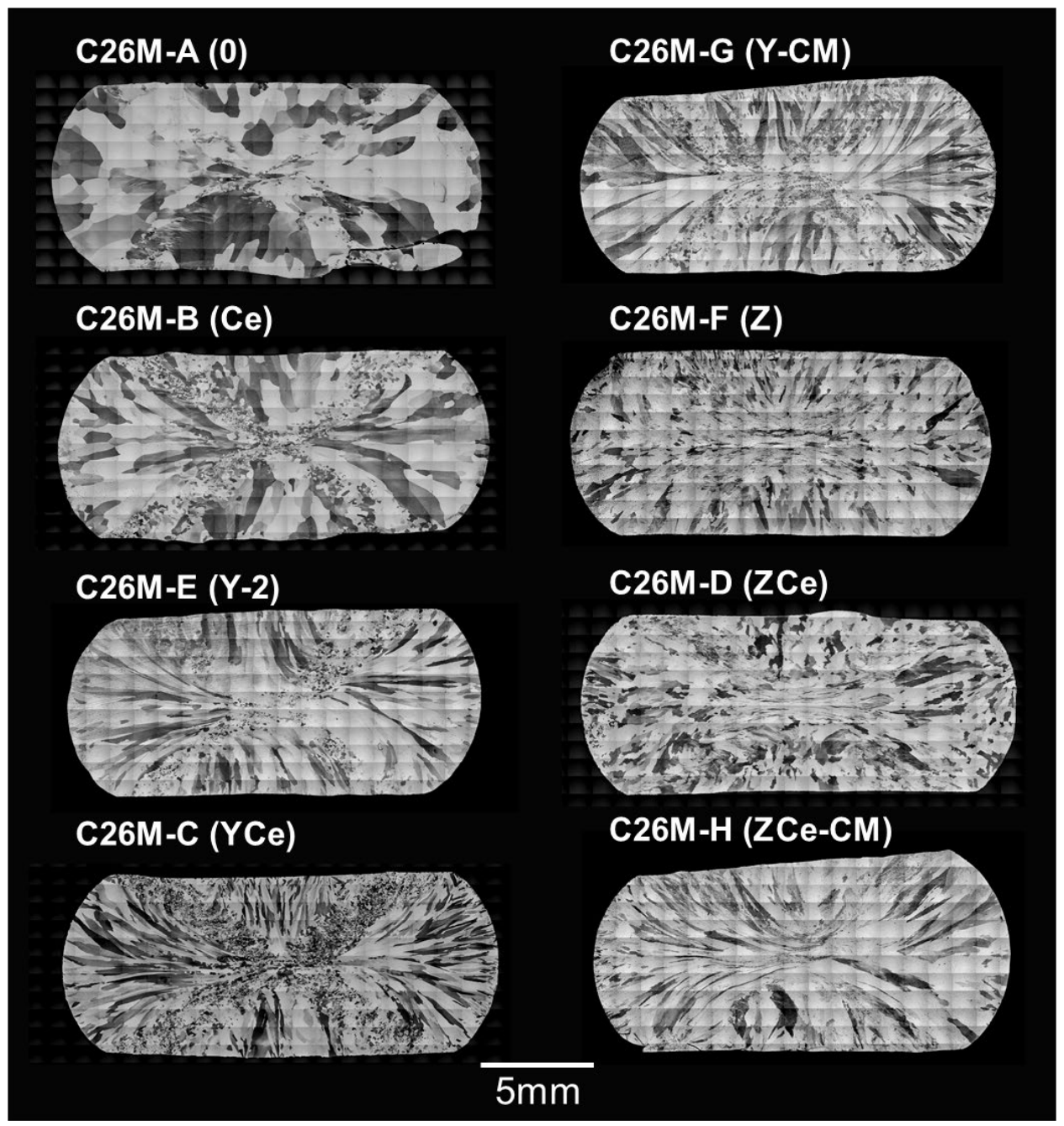

Figure 6. Cross-sectional macrostructure after hot-forging at $800^{\circ} \mathrm{C}$ with $40 \%$ reduction

After applying further hot-forging up to total $70 \%$ reduction, three different microstructural features were observed; (1) very coarse, deformed grain structures observed in C26M-A (0) and -B (Ce), (2) relatively large area of fine recrystallized grain agglomerates combined with elongated, non-recrystallized coarse grains in C26M-E (Y-2), - C (YCe), and -G (Y-CM), and (3) microstructure consisting of heavily deformed grains with almost no recrystallization in C26M-F (Z), C26M-D (ZCe), and C26M-H (ZCe-CM). The group \#1 did not show any sign of grain refinement in the current amount of deformation and required to apply further deformation (i.e. hot-rolling) for further grain structure control. The group \#2 consisted of Y containing alloys, and they started to show a better grain refinement in mostly entire region of the material. The group \#3 consisted of $\mathrm{Zr}$ containing alloys, and they still showed a resistance against dynamic recrystallization at this level of deformation at $800^{\circ} \mathrm{C}$. The feature in the group $\# 3$ could be positive from a grain refinement viewpoint since the high stored energy accumulated from the deformation would boost the nucleation frequency of recrystallized grains. 


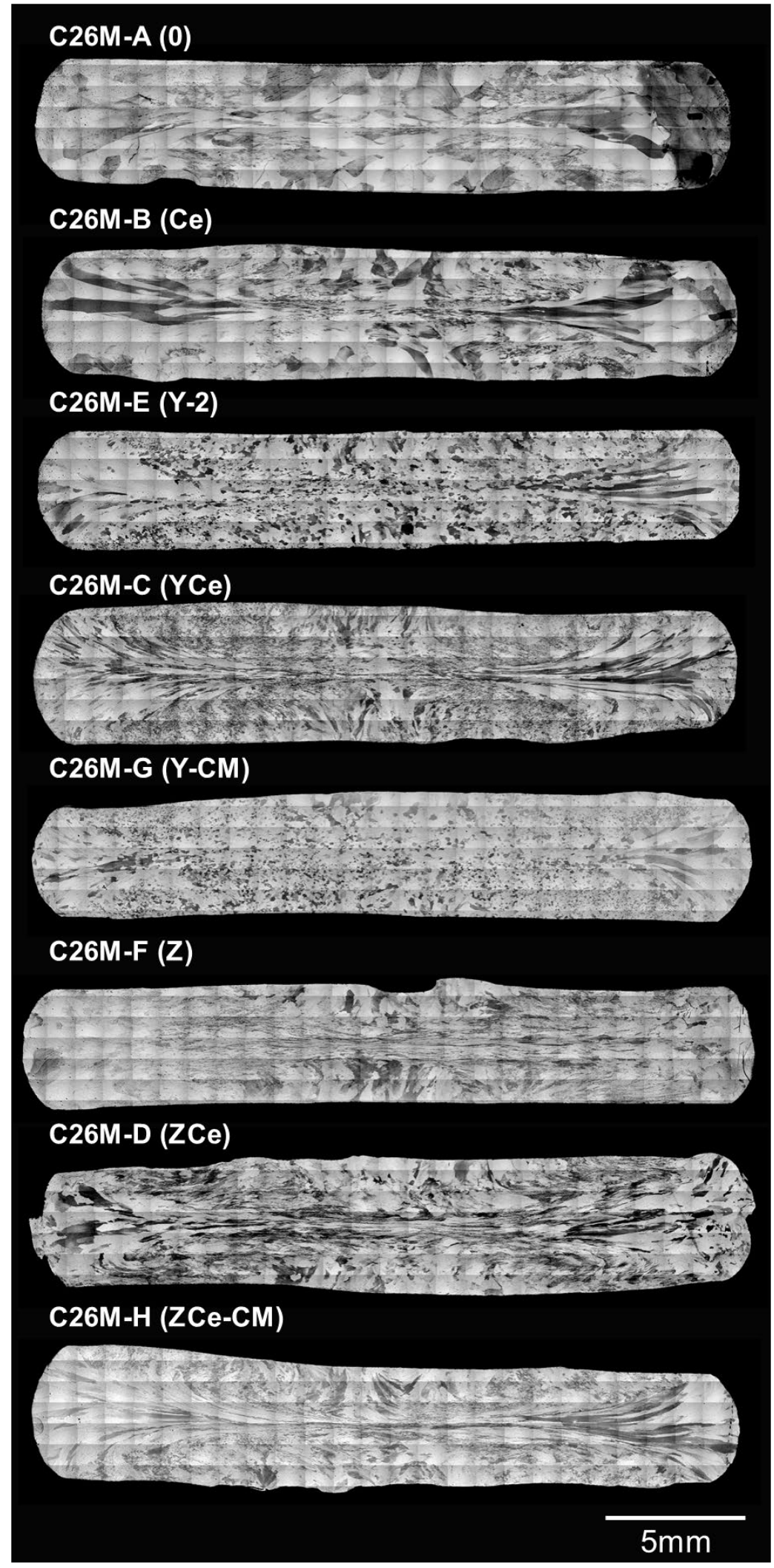

Figure 7. Cross-sectional macrostructure after hot-forging at $800^{\circ} \mathrm{C}$ with $70 \%$ reduction. 


\subsubsection{Recrystallized grain structure after annealing}

Cross-sectional microstructure of selected alloys after applying hot-rolling and annealing were summarized in Figure 8. The microstructures were compared with different final annealing at $800^{\circ} \mathrm{C}, 900^{\circ} \mathrm{C}$, and $1000^{\circ} \mathrm{C}$. C26M-A (0) and C26M-B (Ce) alloys showed uniform, fully recrystallized grain structure at $800^{\circ} \mathrm{C}$ with average grain size of $\sim 30 \mu \mathrm{m}$, and the grains are coarsened after applying $900^{\circ} \mathrm{C}$ annealing with the grain size of more than $\sim 40 \mu \mathrm{m}$. After applying additional annealing at $1000^{\circ} \mathrm{C}$, microstructure consisted of secondary-recrystallized (abnormally coarsened) grains with more than $100 \mu \mathrm{m}$ size. This result indicates that the base composition alloy of Fe-12Cr-6Al-2Mo-0.2Si has a transition temperature of abnormal grain growth between 900 and $1000^{\circ} \mathrm{C}$, and the Ce solo-addition would not change or suppress such characteristics.

Similar grain structure and average grain sizes were observed in C26M-E (Y-2) which also showed a transition of abnormal grain growth between 900 and $1000^{\circ} \mathrm{C}$. On the other hand, the additions of $\mathrm{C}$ and $\mathrm{Mn}$ decreased the average grain size at 800 and $900^{\circ} \mathrm{C}$ compared with the alloy without $\mathrm{C}$ and $\mathrm{Mn}$, suggesting that these elements have an effect to stabilize the fine grain structure. The abnormal grain growth was observed after annealing at $1000^{\circ} \mathrm{C}$, although the microstructure clearly represented the effect of the $\mathrm{C}$ and $\mathrm{Mn}$ additions on stabilizing the grain structure.

The alloys with the $\mathrm{Zr}$ addition exhibited quite different microstructure evolution compared to the others. Microstructure of C26M-F (Z) and C26MZx (YZCe-CM) after annealing at $800^{\circ} \mathrm{C}$ consisted mostly of nonrecrystallized grains, even with $90 \%(\mathrm{Z})$ or $94 \%$ (YZCe-CM) of total reduction at $800^{\circ} \mathrm{C}$, suggesting that the effect of the $\mathrm{Zr}$ addition on stabilizing the deformed grains are significantly high. Prolonged annealing at $800^{\circ} \mathrm{C}$ up to $60 \mathrm{~min}$ did not show significant changes in the microstructure. After annealing at $900^{\circ} \mathrm{C}$, they finally showed fully recrystallized microstructure with average grain size of 20-25 $\mu \mathrm{m}$, and additional annealing at $1000^{\circ} \mathrm{C}$ for $30 \mathrm{~min}$ did not change the average grain size.

The average grain sizes of all alloys were summarized in Table 4 and plotted in Fig. 9. The results showed a clear trend that the $\mathrm{Zr}$ addition is effective to refine and stabilize the grain structure up to $1000^{\circ} \mathrm{C}$ annealing. 


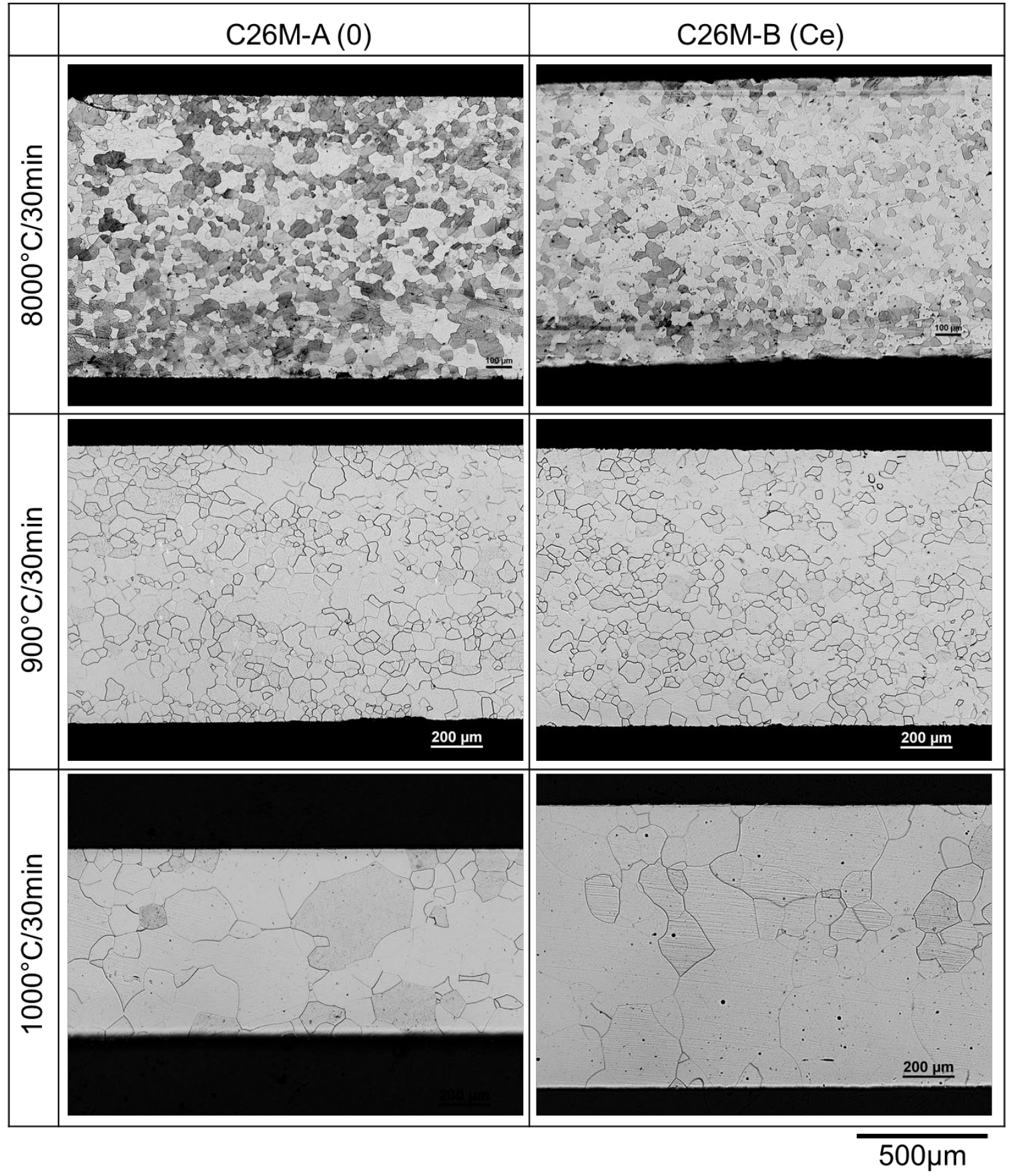

Figure 8. Cross-sectional microstructures of the rolled-and-annealed alloys at three different final annealing temperatures $(1 / 3)$. 


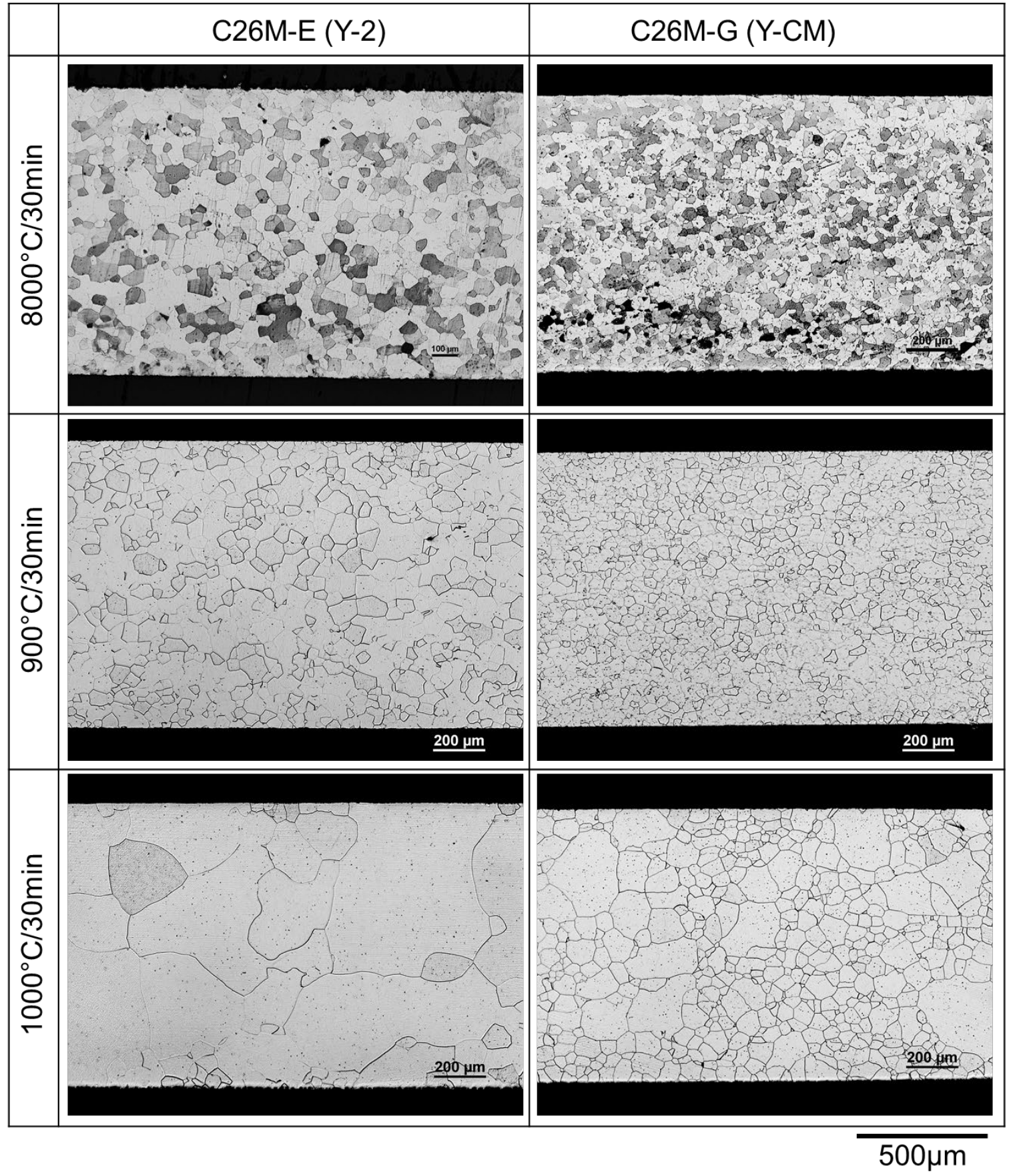

Figure 8. Cross-sectional microstructures of the rolled-and-annealed alloys at three different final annealing temperatures $(2 / 3)$. 


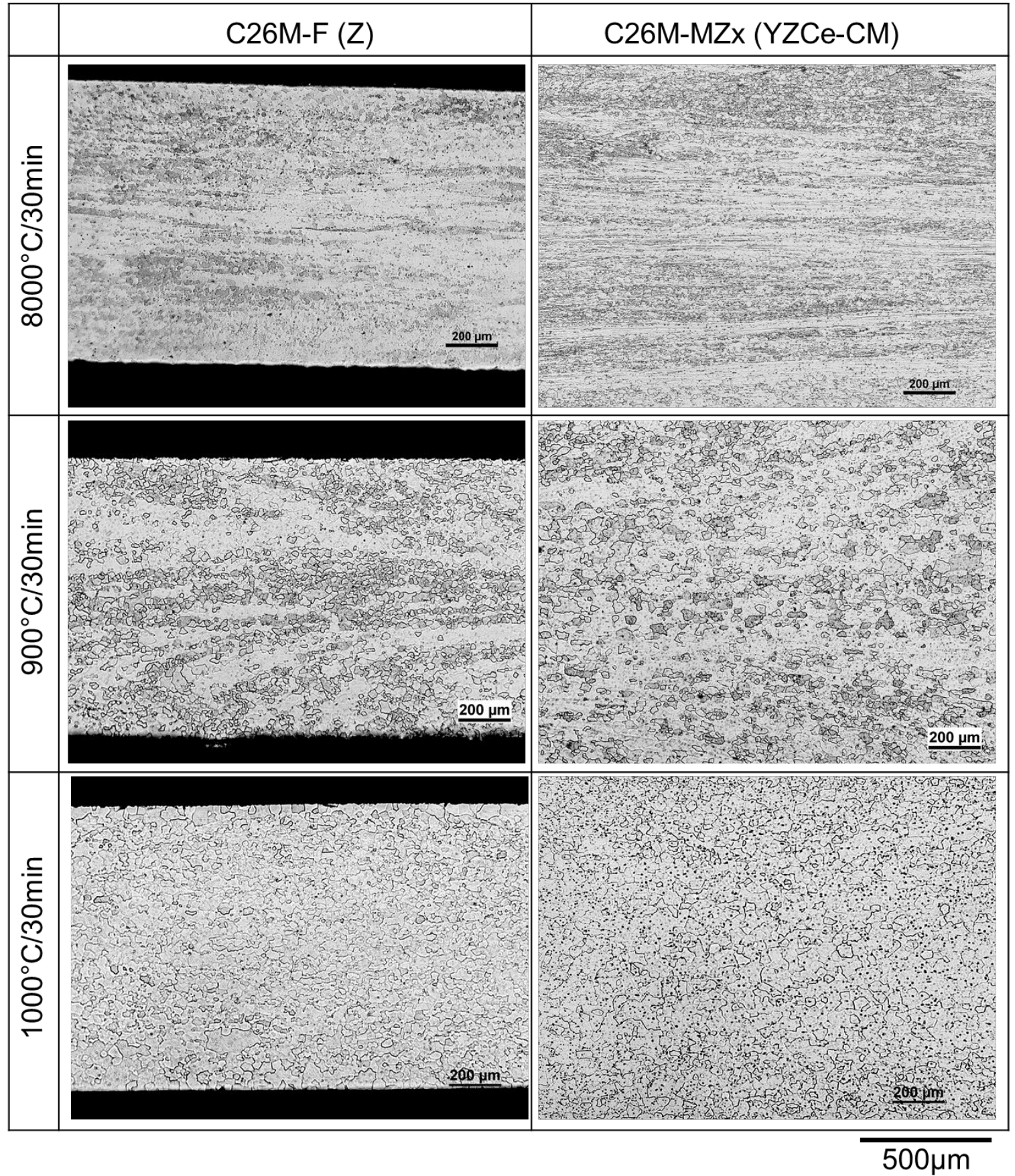

Figure 8. Cross-sectional microstructures of the rolled-and-annealed alloys at three different final annealing temperatures $(3 / 3)$. 
Table 4. Average grain size of the rolled-and-annealed materials; the highlighted samples were used for the tensile property evaluation and the ramp testing, and the masked samples showed not fully recrystallized microstructure.

\begin{tabular}{cccccc}
\hline & & \multicolumn{5}{c}{ Grain size, $\mu \mathrm{m}$} \\
\cline { 3 - 6 } Name & Short ID & $\begin{array}{c}800^{\circ} \mathrm{C}- \\
30 \mathrm{~min}\end{array}$ & $\begin{array}{c}800^{\circ} \mathrm{C}- \\
60 \mathrm{~min}\end{array}$ & $\begin{array}{c}800^{\circ} \mathrm{C}-30 \mathrm{~min}+ \\
900^{\circ} \mathrm{C}-30 \mathrm{~min}\end{array}$ & $\begin{array}{l}800^{\circ} \mathrm{C} \text { or } 900^{\circ} \mathrm{C}- \\
30 \mathrm{~min}+1000^{\circ} \mathrm{C}- \\
30 \mathrm{~min}\end{array}$ \\
\hline C26M-A & $\mathbf{0}$ & $\mathbf{3 0 . 2}$ & 30.1 & 44.4 & $\mathbf{1 0 6 . 5}$ \\
\hline C26M-B & $\mathbf{C e}$ & $\mathbf{2 9 . 0}$ & 29.7 & 33.2 & $\mathbf{1 2 7 . 5}$ \\
\hline C26M3 & $\mathbf{Y}$ & $\mathbf{3 8 . 2}$ & 37.0 & 44.5 & \\
\hline C26M-E & Y-2 & 37.4 & 34.6 & $\mathbf{4 8 . 4}$ & $\mathbf{9 3 . 5}$ \\
\hline C26M-C & YCe & 19.6 & 17.0 & $\mathbf{2 7 . 3}$ & \\
\hline C26M-G & Y-CM & 24.5 & 25.6 & $\mathbf{3 0 . 0}$ & $\mathbf{5 6 . 4}$ \\
\hline C26Mx & YCe-CM & 25.0 & 27.2 & $\mathbf{3 4 . 8}$ & \\
\hline C26M-F & $\mathbf{Z}$ & 11.1 & 9.7 & $\mathbf{2 0 . 5}$ & $\mathbf{1 4 . 9}$ \\
\hline C26M-D & ZCe & 3.0 & 9.2 & $\mathbf{2 0 . 9}$ & \\
\hline C26M-H & ZCe-CM & 16.6 & 20.6 & $\mathbf{2 2 . 9}$ & \\
\hline C26MZ & YZCe & 5.0 & 10.0 & $\mathbf{2 0 . 9}$ & $\mathbf{2 6 . 7}$ \\
\hline C26MZx & YZCe-CM & 5.0 & 25.0 & $\mathbf{2 5 . 5}$ & \\
\hline
\end{tabular}

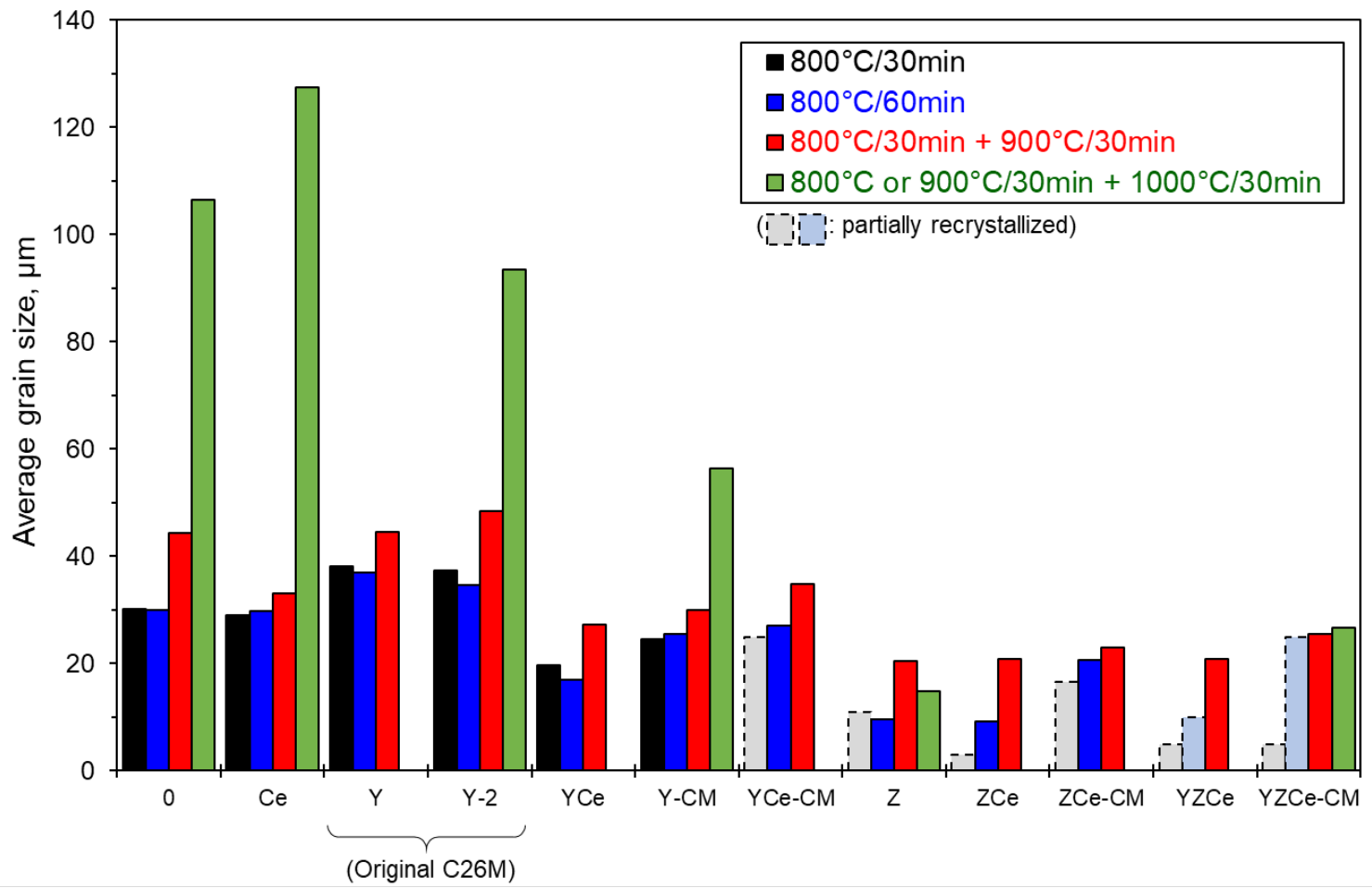

Figure 9. Average grain size of the rolled-and-annealed materials. 


\subsection{Room temperature tensile properties}

Tensile tests of the alloys with selected annealing conditions were conducted at room temperatures. The annealing condition was selected to form a fully recrystallized microstructure combined with as small grain size as possible for each alloy, expecting better ductility. All tensile properties were plotted in Fig. 10. The results indicated no significant variation among the alloys in the yield strength (YS) and the ultimate tensile strength (UTS). On the other hand, some variation can be seen in the uniform plastic elongation (UE) and total plastic elongation (TE). These tensile properties were replotted as a function of the average grain size, as shown in Fig. 11. Both YS and UTS showed no significant dependence of average grain size, whereas the UE showed a strong negative dependence of the grain size as expected. The alloys with the $\mathrm{Zr}$ additions clustered at the left upper side and on a line showing the trend of the grain size effect, suggesting that the improvement of ductility came mainly from the grain refinement rather than the other factors attributed to the variation of alloying additions. The plot at the right end corresponds to the original C26M alloy (C26ME) with the average grain size of $48.4 \mu \mathrm{m}$, so that nearly $50 \%$ of ductility improvement has been obtained by applying the grain refinement through minor alloying additions.
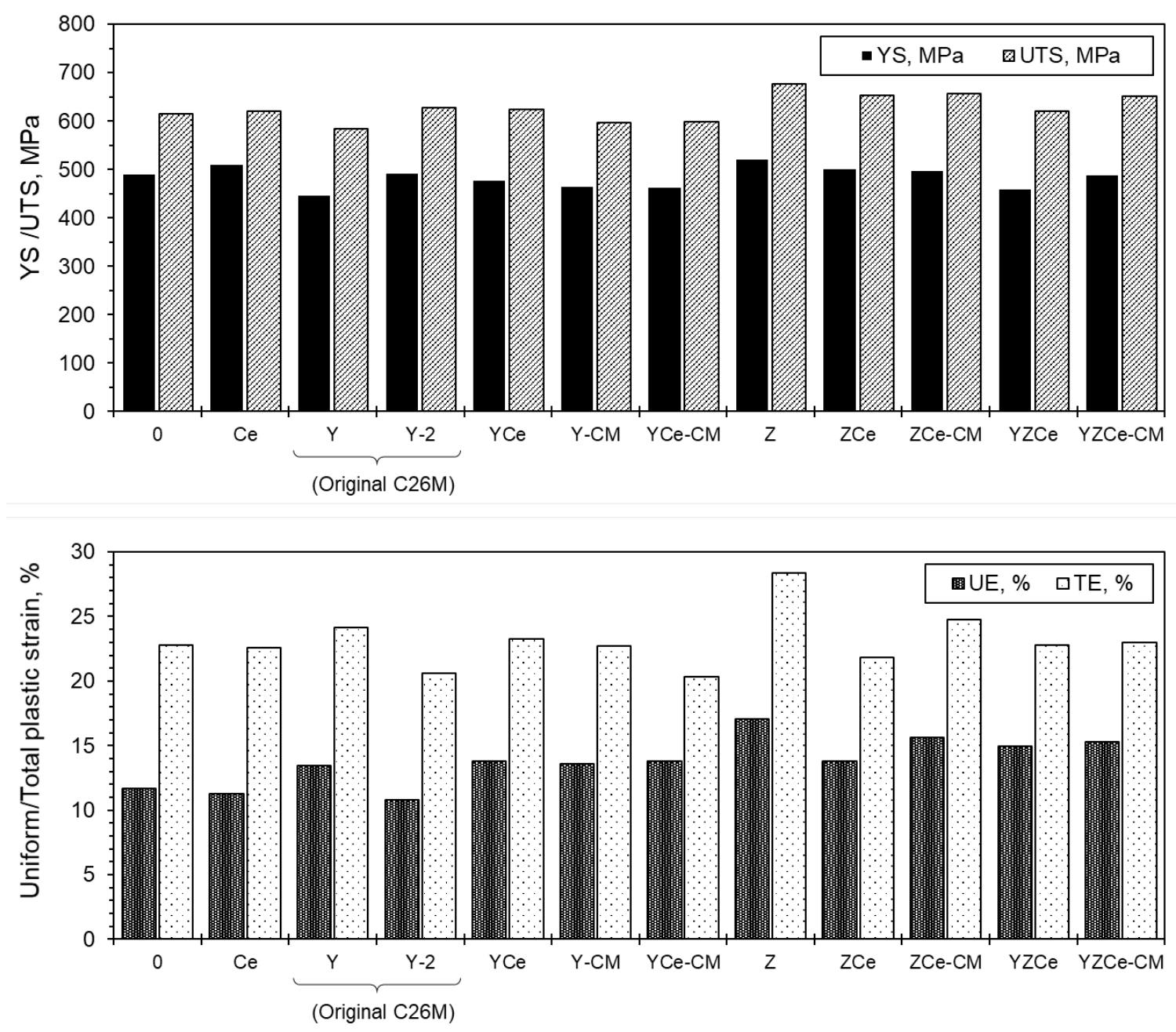

Figure 10. Room temperature tensile properties of all alloys in the present study. 

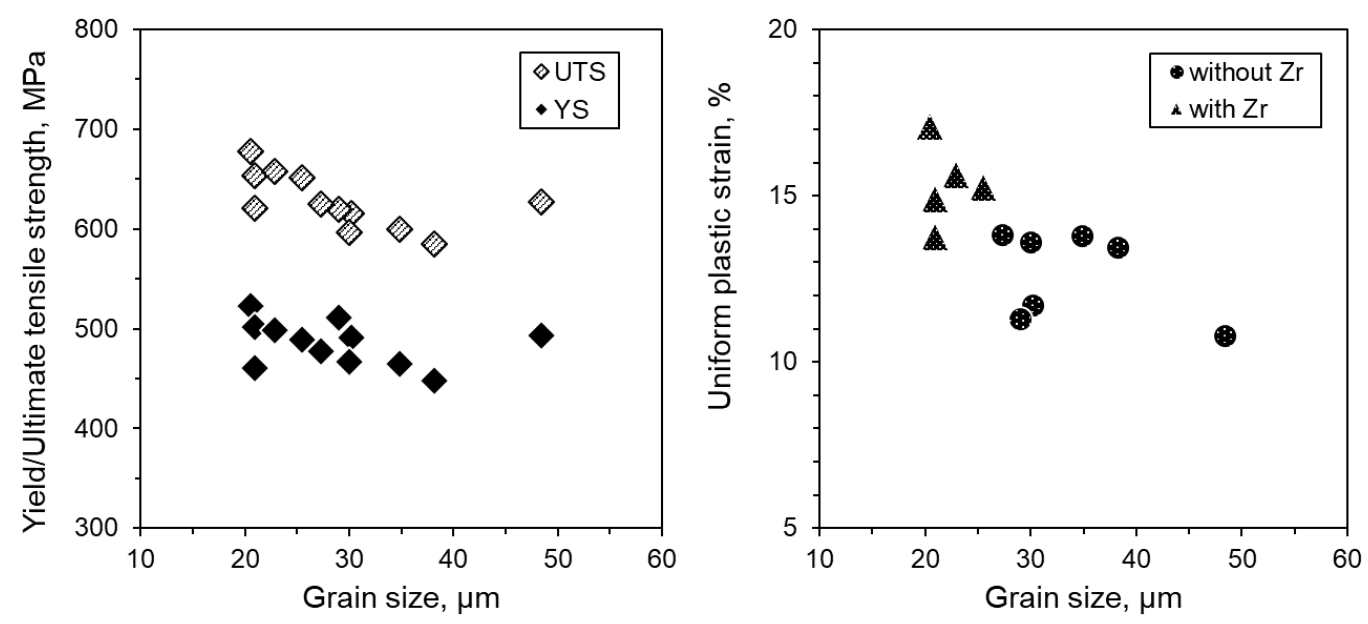

Figure 11. Room temperature tensile properties plotted as a function of average grain size.

\subsection{Ramp test}

Ramp test was conducted to evaluate the effect of minor alloying additions on oxidation resistance. The test conditions in the present study followed the latest test trends used in the Severe Accident Test Station (SATS) at Oak Ridge National Laboratory [11]. The alloys were annealed at the same conditions for the tensile test specimens. Only C26M-A (0) was tested up to $1400^{\circ} \mathrm{C}$ because it was heavily damaged at the temperature, but the other alloys were tested up to $1450^{\circ} \mathrm{C}$.

The pictures of the tested coupon specimens are shown in Fig. 12. As noted above, C26M-A (0) was heavily oxidized and/or melted. The Ce solely-added alloy [C26M-B (Ce)] showed a surface color change but almost no sign of non-protective oxide nodule formation. The Y containing alloys including C26M3 (Y), C26M-C (YCe), C26M-G (Y-CM), and C26Mx (YCe-MX) showed very similar surface color to each other, which indicated a potential protective characteristics of the alloys at the test condition. On the other hand, the alloys with Zr including C26M-F (Z), C26M-D (ZCe), C26MZ (YZCe), C26M-H (ZCe-CM), and C26MZx (YZCe-CM) showed significant surface color changes, and some of them showed a partially segregated attack of the oxidation near the hole. The attack near the hole could be attributed to the potential reaction of the alloys with the $\mathrm{SiC}$ rods used for the specimen support during the testing.

The mass changes of the alloys are also shown in Fig. 13. The alloys with no Zr additions, other than C26MA (0), showed relatively small mass gains after testing, which are consistent with the visual inspection in Fig. 12. The Y containing alloys did not show a significant variation among the alloys, indicating that the effect of the additional minor elements $(\mathrm{Ce}, \mathrm{C}$, and $\mathrm{Mn}$ ) on the oxidation resistance was significantly small. However, the Ce solo-addition showed mass loss after testing, suggesting that Ce does not stabilize the protective alumina scale. The alloys with the $\mathrm{Zr}$ additions, on the other hand, showed significant mass gain. However, the results did not capture the degree of surface protection of these alloys because of the partial melt in the alloys C26M-D (ZCe), C26MZ (YZCe), and C26M-H (ZCe-CM) which significantly impact on the mass gain. 


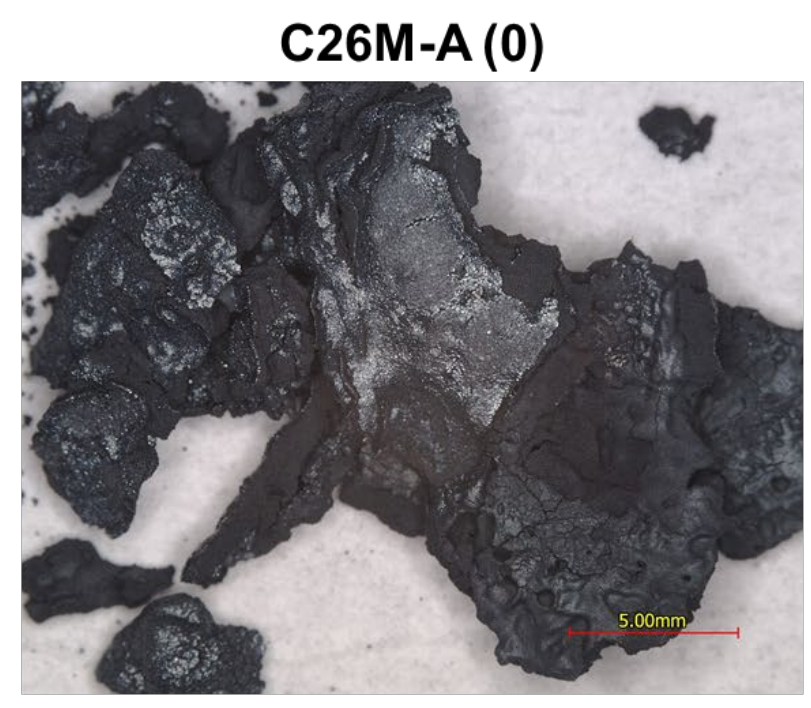

C26M3 (Y, original)

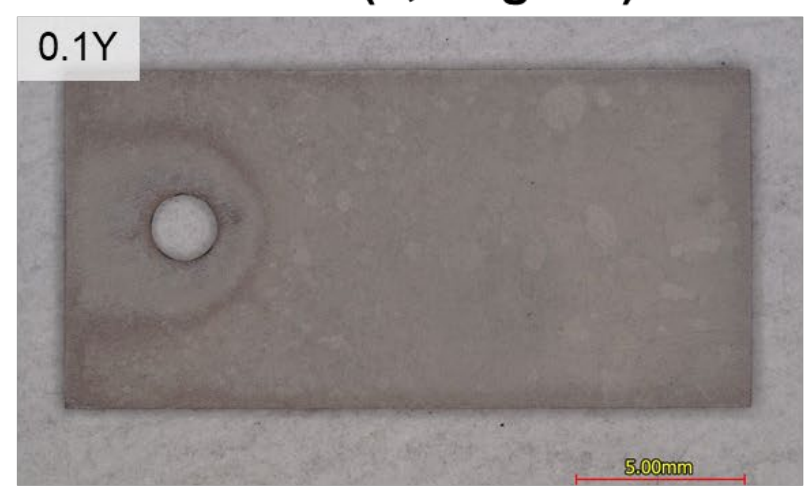

$\mathrm{C} 26 \mathrm{M}-\mathrm{C}$ (YCe)

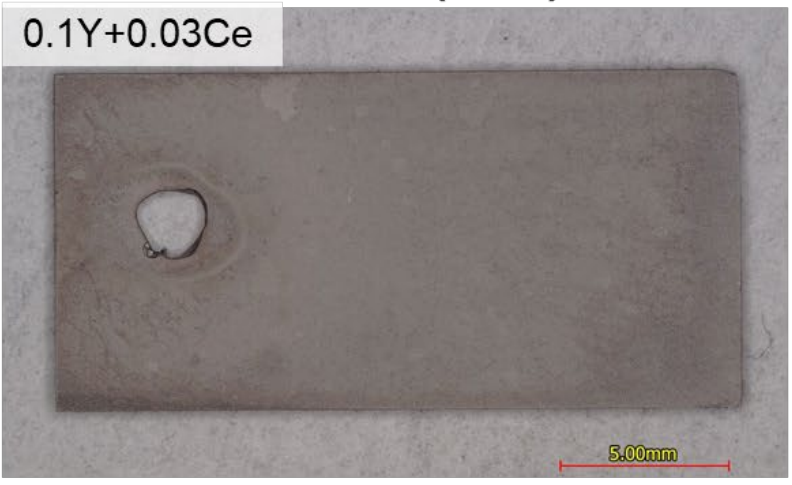

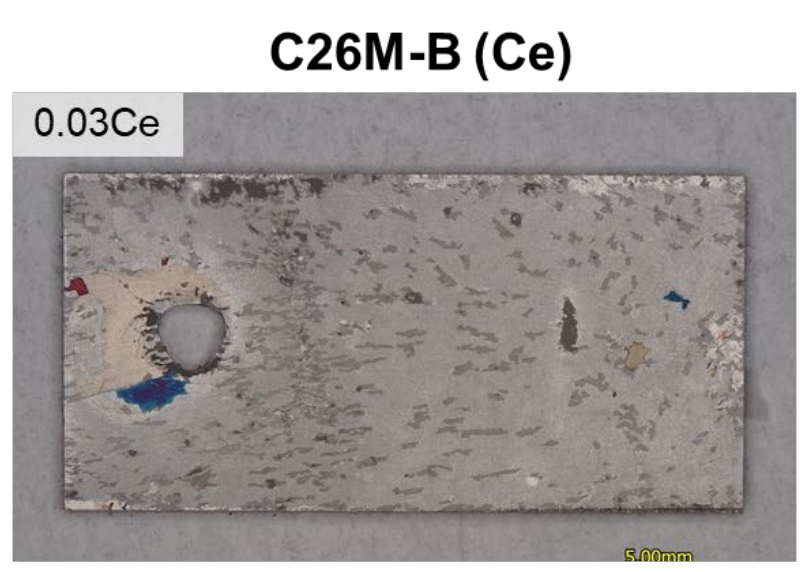

C26M-G (Y-CM)

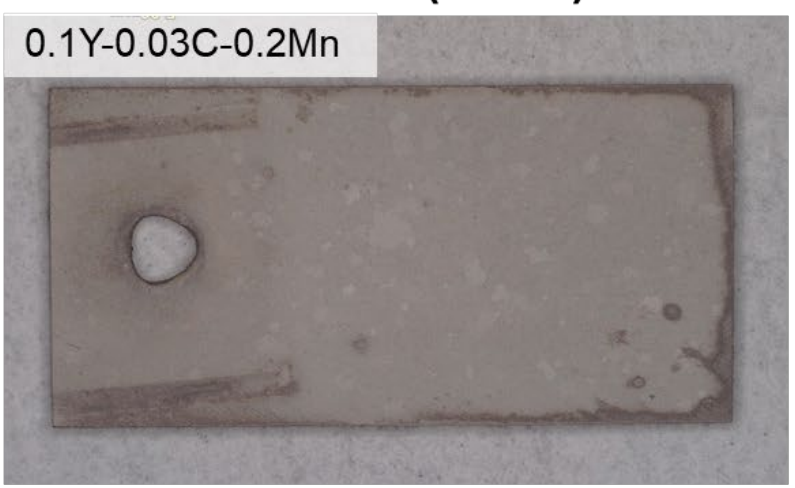

$\mathrm{C} 26 \mathrm{Mx}$ (YCe-CM)

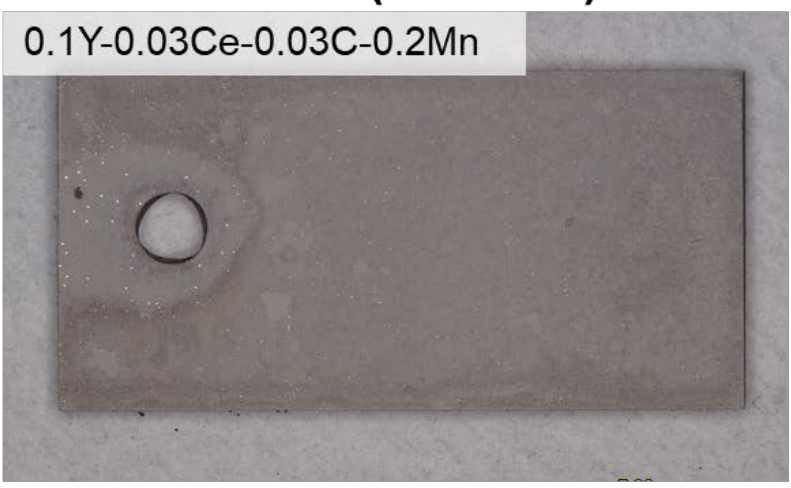

$5 \mathrm{~mm}$

Figure 12. Pictures of the ramp-tested coupon specimens (1/2). 

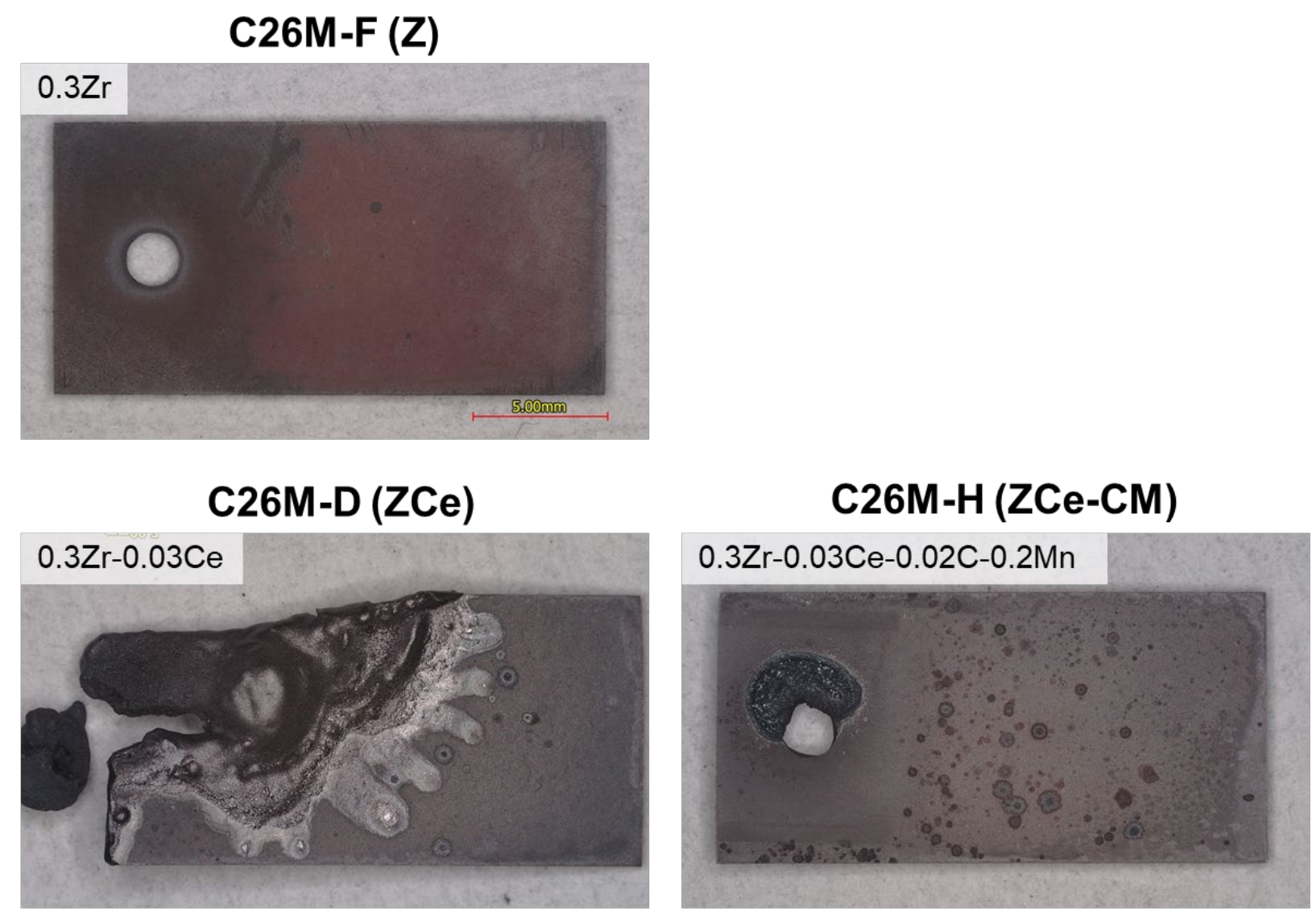

\section{$\mathrm{C26MZ}$ (YZCe)}

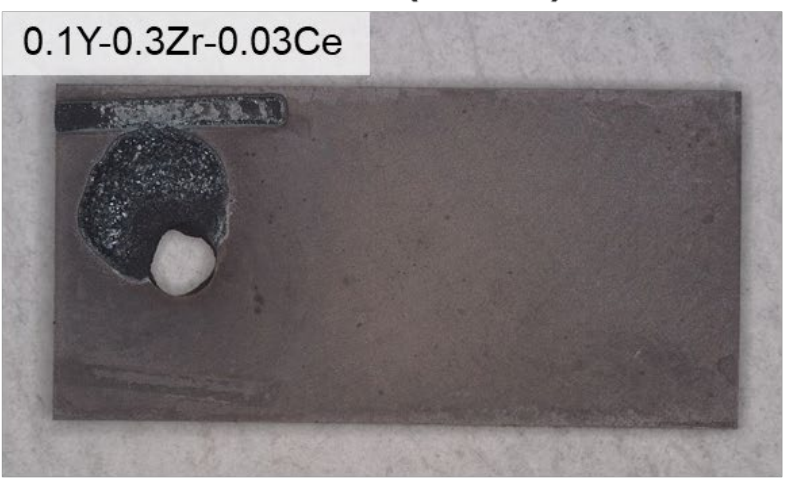

\section{C26MZx (YZCe-CM)}

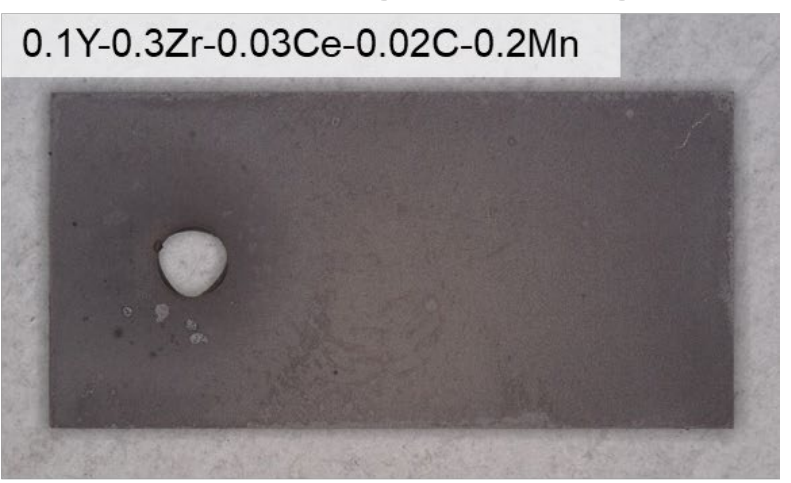

\section{$5 \mathrm{~mm}$}

Figure 12. Pictures of the ramp-tested coupon specimens (2/2). 


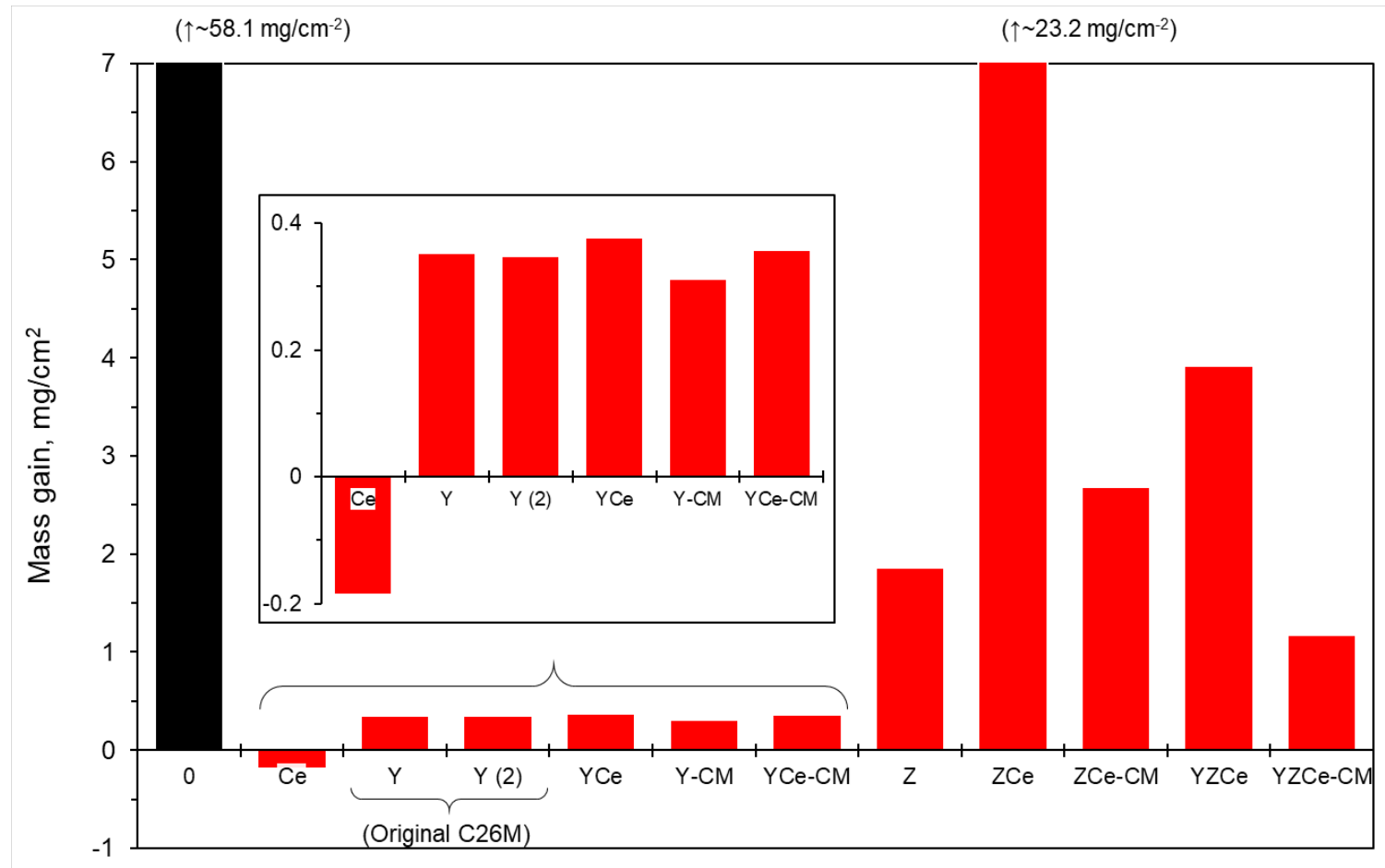

Figure 13. Mass gains of the specimens after ramp testing.

Based on the results above, the cross-sectional microstructure characterization of the tested specimens was conducted. The specimens for the alloys with the $\mathrm{Zr}$ additions were sectioned sufficiently away from the hole or the area of melted features.

The low and high magnifications of the cross-sectional micrographs are summarized in Fig. 14. All specimens showed very coarse grain structure because of the exposure at very high temperature. The alloy C26M-B (Ce) did not show any surface oxide scale but did have a non-smooth surface. By combining with the results of mass loss in Fig. 13, the surface of this alloy might reach a stable, local equilibrium condition balancing the protective surface scale formation and volatilization, which could maintain no internal attack of oxidation. The alloys with $\mathrm{Y}, \mathrm{Y}+\mathrm{Ce}, \mathrm{Y}+\mathrm{C}+\mathrm{CM}$, and $\mathrm{Y}+\mathrm{Ce}+\mathrm{C}+\mathrm{Mn}$ showed very similar continuous surface oxide formation, presumably alumina-scale, with the thickness in a range from 1.5 to $2.5 \mu \mathrm{m}$, and no internal oxide formation were observed. For the alloys with $\mathrm{C}$ and $\mathrm{Mn}(\mathrm{C} 26 \mathrm{M}-\mathrm{F}$ and $\mathrm{C} 26 \mathrm{Mx})$, they show a little amount of oxide penetration along the grain boundary, although there seemed no negative impact on the macroscopic oxidation resistance. On the other hand, the alloys containing $\mathrm{Zr}$ showed relatively thick and non-protective oxide formation with $\sim 5 \mu \mathrm{m}$ thickness, combined with a significant internal oxide formation with more than $10 \mu \mathrm{m}$ depth from the surface. For the alloys with $\mathrm{Y}+\mathrm{Ce}+\mathrm{Zr}$, the low magnification images indicated a partial melt along the grain boundary (dark contrast regions), and it might cause deep penetration of the internal attack along the grain boundary. Therefore, excess total amounts of reactive elements could negatively impact both the oxidation resistance and the potential mechanical property degradation due to melting at elevated temperatures. 


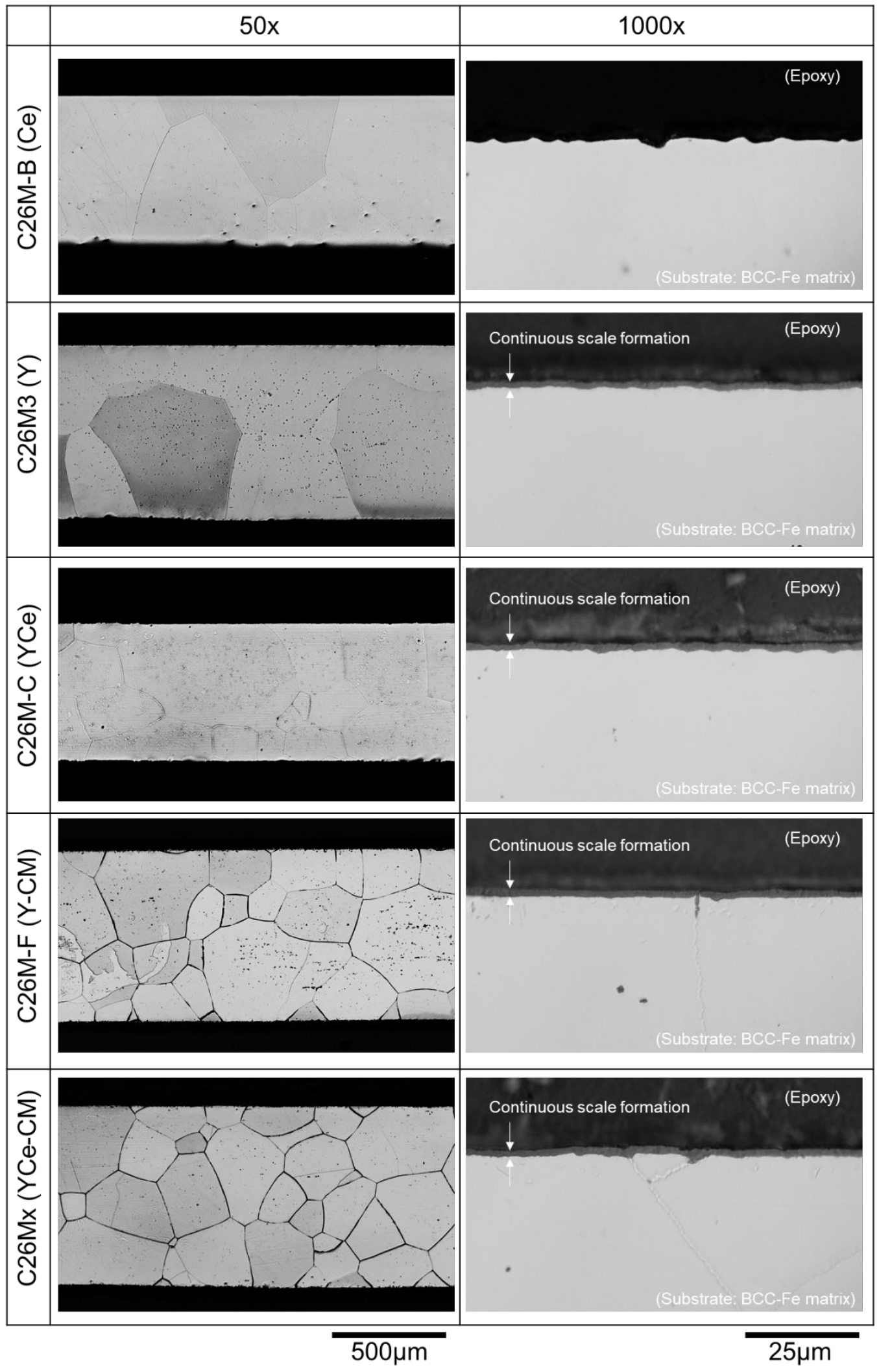

Figure 14. Low and high magnification optical micrographs of the cross-sectional surface region of the ramp-tested coupon specimens (1/2). 


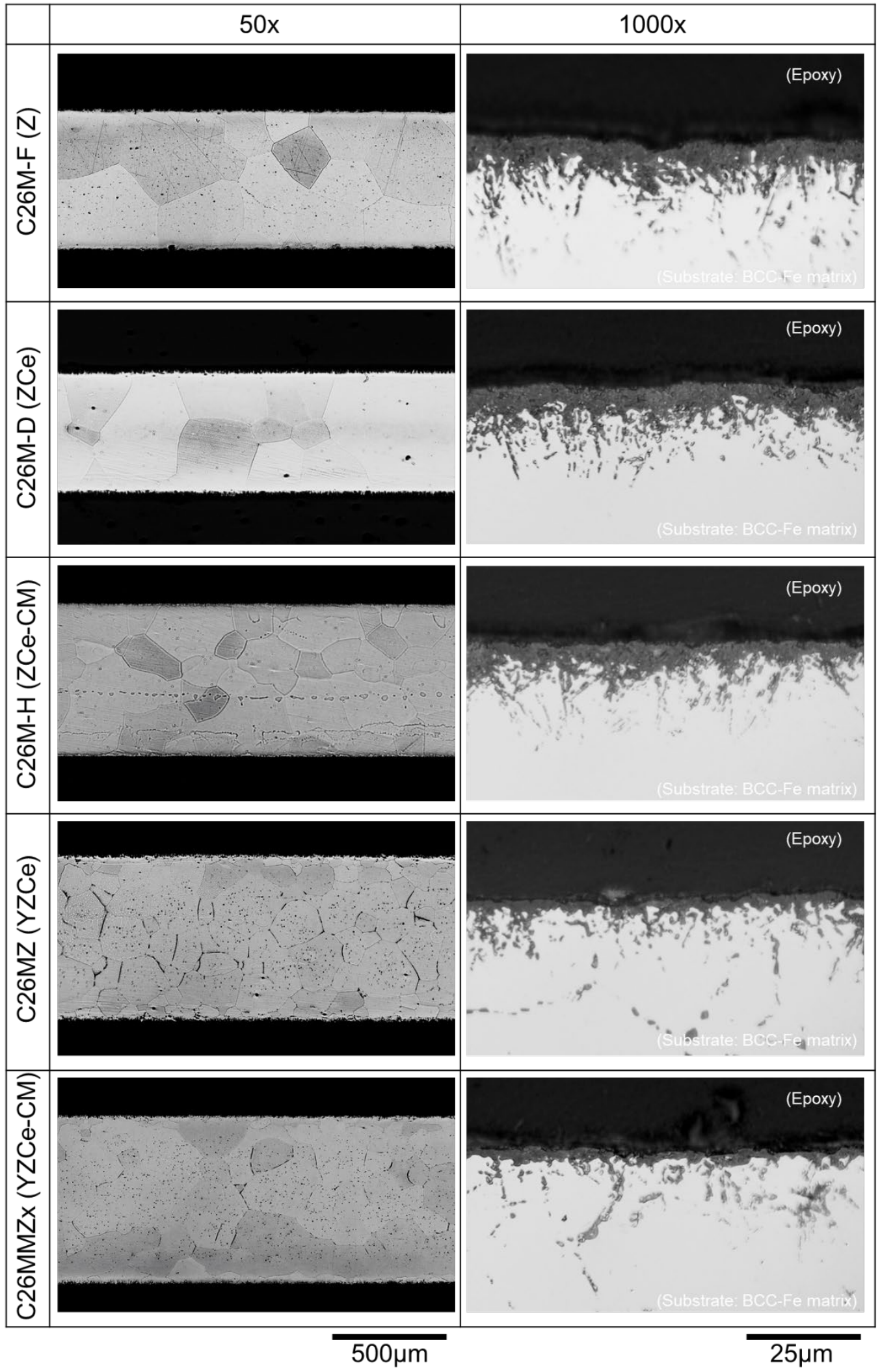

Figure 14. Low and high magnification optical micrographs of the cross-sectional surface region of the ramp-tested coupon specimens (2/2). 
Based on these results, the positive and negative impacts of minor alloying additions ( $\mathrm{Y}, \mathrm{Ce}, \mathrm{Zr}, \mathrm{C}$, and $\mathrm{Mn}$ ) for microstructure control, tensile properties, and oxidation resistance, were experimentally captured. The obtained parameters can be used to optimize the processability of $\mathrm{C} 26 \mathrm{M}$ base $\mathrm{FeCrAl}$ alloy seamless tube production balanced with the improved properties of the final product.

\subsection{Thermophysical properties}

In addition to the exploration of minor alloying effects on the properties, the additional evaluation of thermophysical properties of the base "C26M" alloy was conducted, as a part of the effort to update the "Handbook on the Material Properties of FeCrAl Alloys for Nuclear Power Production Applications [8]" prepared and updated under Advanced Fuels Campaign, Office of Nuclear Energy, US-DOE.

The measurement results of thermal expansion, specific heat capacity, and thermal diffusivity were summarized, as a function of temperature, in Fig. 15. The thermal expansion coefficient (CTE) during heating showed a good agreement with the other types of FeCrAl alloys in the handbook [8]. The cooling results showed discrepancy from the heating results, and the gap becomes larger at relatively lower temperature. The mechanism of the gap is unknown, but almost the same gaps have been identified from three different test samples, indicating that the results captured the actual thermal properties. It is speculated that the microstructure change during exposure might affect to the CTE value during cooling. The specific heat capacity showed a peak at $\sim 580^{\circ} \mathrm{C}$, which corresponded to the Curie temperatures. The curve below the Curie temperature will be fitted with a simple third-order polynomial equation $\left(C \mathrm{p}=\mathrm{a} T+\mathrm{b} T^{2}+\mathrm{c} T^{3}\right)$, and the three constants will be compared with the other alloys reported in the handbook. The thermal diffusivity measurement was also conducted multiple times, and consistent test results were obtained. The Curie temperature was also consistent with the other test results. The data will be used to calculate the thermal conductivity as a function of the temperature and updated in the next handbook revision.
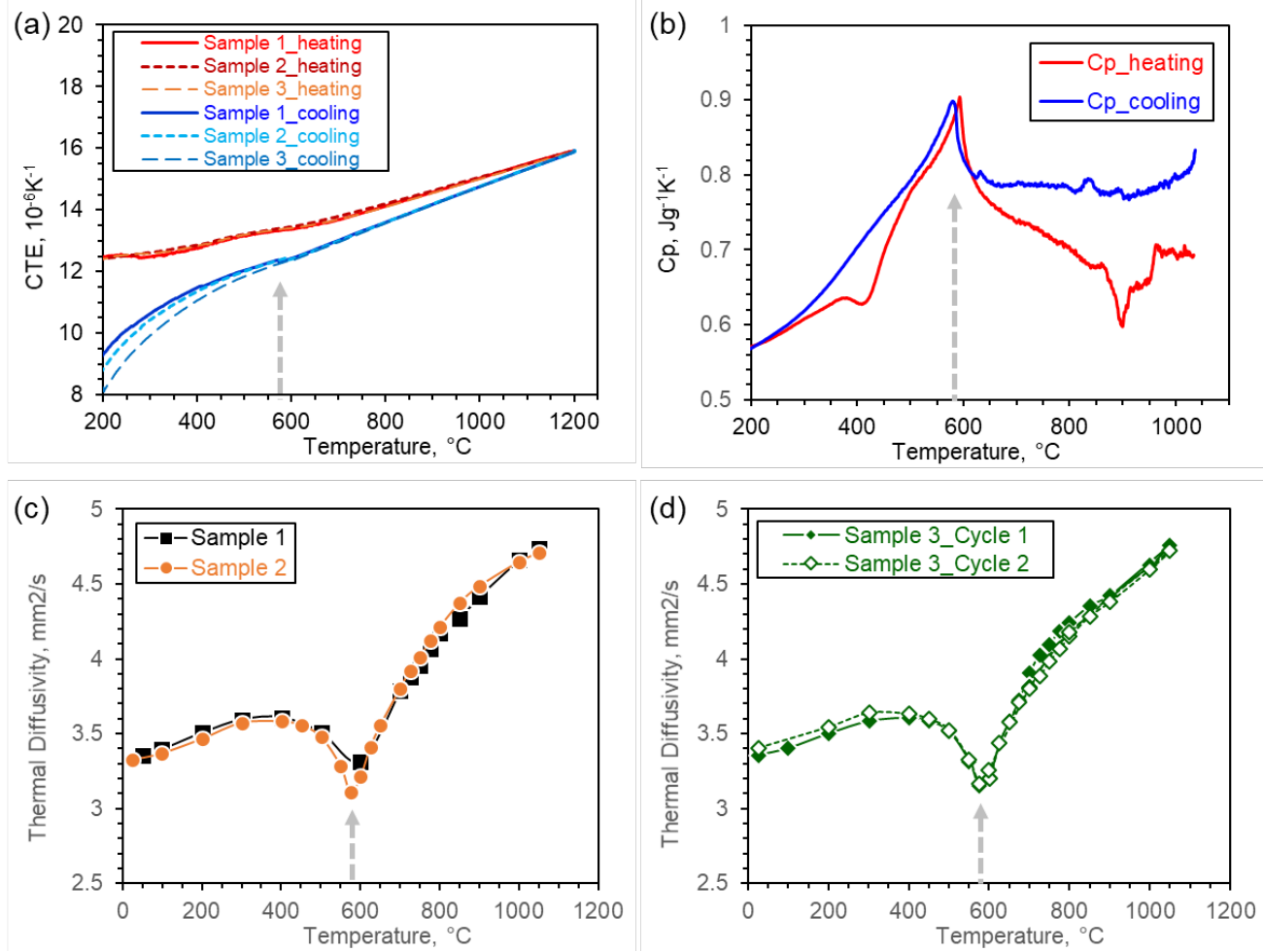

Figure 15. Thermo-physical properties of C26M2 as a function of temperature; (a) coefficient of thermal expansion, (b) specific heat capacity, and (c, d) thermal diffusivity. 


\section{Summary}

In this report, new FeCrAl heat variants with minor alloying additions have been explored to investigate positive and negative impacts on various properties including microstructure evolution, mechanical properties, and oxidation resistance. It targets the improvement of the processability of seamless, thin-wall wrought $\mathrm{FeCrAl}$ alloy production based on $\mathrm{C} 26 \mathrm{M}$ (Fe-12Cr-6Al-2Mo-0.2Si-0.03Y, wt.\%), balanced with the properties of final product.

Total 12 lab-scale heats of $\mathrm{C} 26 \mathrm{M}$ base $\mathrm{FeCrAl}$ alloys with various combinations of minor alloying elements were prepared by arc-melting, and then microstructure evolution from as-cast material, hot-forged, -rolled, and then annealed at 800,900 , and $1000^{\circ} \mathrm{C}$ was evaluated. It was found that the addition of $0.03 \mathrm{wt} . \% \mathrm{Y}$ dominantly controlled the solidification microstructure consisting only of the columnar grains, and it caused inhomogeneous material deformation (and therefore microstructure evolution) during hot-process. On the other hand, the addition of $0.3 \mathrm{wt} . \% \mathrm{Zr}$ promoted the formation of equi-axed grains in the as-cast material, supported more homogeneous deformation during hot-process, and significantly improved the stability of fine, recrystallized grain structure with $\sim 20-25 \mu \mathrm{m}$ of average grain size. The grain refinement increases the room-temperature ductility, and the grain size stability during exposure at elevated temperature allows a wide process condition of various hot-process, including seamless, thin-wall $\mathrm{FeCrAl}$ tube production (e.g. large drawing reduction per pass, wide tolerance of annealing conditions, etc.). However, the $\mathrm{Zr}$ addition was also found decreasing the oxidation resistance during ramp test in steam environment up to $1450^{\circ} \mathrm{C}$, whereas the $\mathrm{Y}$ added alloys (with no $\mathrm{Zr}$ ) showed improved oxidation resistance with protective aluminascale formation. Because of the observed improved properties, the present results still hold an opportunity to optimize the balanced, further improved properties by fine tuning of minor alloying additions. In addition, the $\mathrm{C}$ and $\mathrm{Mn}$ additions simulating an industrial-grade alloy production did not show a strong impact on changing the properties, suggesting the additional compositional tolerance in the alloy specification.

As part of the updating efforts of $\mathrm{FeCrAl}$ handbook, thermophysical property measurements of $\mathrm{C} 26 \mathrm{M}$ alloy were conducted. The thermal expansion coefficient, specific heat capacity, and thermal diffusivity were measured as a function of temperature, and the results showed a good agreement with the other FeCrAl alloys with similar composition range, reported in the previous handbook. The data will be used for the next update of the handbook. 


\section{REFERENCES}

[1] D. Powers and R. Meyer, Cladding swelling and rupture models for LOCA analysis, NUREG-0630; U. S. Nuclear Regulatory Commission: 1980.

[2] B. A. Pint, K. A. Unocic and K. A. Terrani, Materials at High Temperature, Vol. 32 (2015) 28-35.

[3] M. Moalem, D. R. Olander, Journal of Nuclear Materials, Vol. 182 (1991) 170.

[4] K. Suzuki, S. Jitsukawa, N. Okubo, F. Takada, J. Nucl. Eng. and Design, Vol. 240 (2010) 12901305.

[5] Y. Yamamoto, B. A. Pint, K. Terrani, K. G. Field, L. L. Snead, "Letter report documenting identifying billets and alloys fabricated for distribution to program" M3FT-13OR0202291, ORNL/LTR-2013/322, Oak Ridge National Laboratory (2013).

[6] Y. Yamamoto, Z. Sun, "Quality Optimization of Commercial FeCrAl Tube Production," M3FT17OR020202121, ORNL/TM-2017/338, Oak Ridge National Laboratory (2017).

[7] H. Qu, Y. Lang, C. Yao, H. Chen, C. Yang, Materials Science and Engineering: A 562 (2013) 9-16.

[8] K. Field, "Handbook on the Material Properties of FeCrAl Alloys for Nuclear Power Production Applications (FY18 Version, Revision 1)," ORNL/SPR-2018/905, Oak Ridge National Laboratory (2018).

[9] Z. Shaohua, Y. Yanchong, W. Shebin, L. Hao, Journal of Rare Earths, Vol. 35, No. 5 (2017) 518524.

[10] S. Yan, N. Li, J. Wang, J. Yan, W. Liu, D. Li, X. Mou, L. Ying, X. Zhao, Journal of Alloys and Compounds, Vol. 740 (2018) 587-594.

[11] M. Sneed, Y. Yan, M. Howell, J.R. Keiser, K.A. Terrani, "Severe Accident Test Station Design Document," ORNL/TM-2015/556, Oak Ridge National Laboratory (2015). 